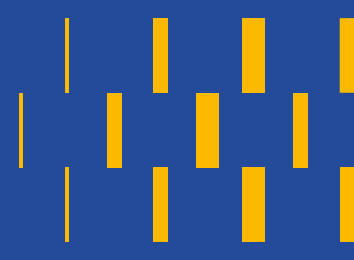

\title{
Indagaciones en torno al significado del oro en la cultura mapuche. Una exploración de fuentes y algo más
}

\section{Inquiries on the Meaning of Gold in Mapuche Culture. A review of sources and something more}

\author{
Gertrudis Payàs Puigarnau ${ }^{1}$ (D) https://orcid.org/0000-0002-9117-8108 \\ Belén Villena Araya ${ }^{2}$ (D) https://orcid.org/0000-0002-4295-2531 \\ ${ }^{1}$ Universidad Católica de Temuco, Temuco, CHILE. Email: gpayas@uct.cl \\ ${ }^{2}$ Pontificia Universidad Católica de Valparaíso, Valparaíso, CHILE. Email: belen.villena@gmail.com
}

No se les ve jamás nada de oro. Existe una idea generalizada de que no usan el oro porque lo consideran la causa de todas sus guerras con los espańoles y desean ocultar la existencia de ese metal en su territorio (Reuel Smith, 1914, p. 94).

\section{Resumen}

El proyecto interdisciplinar (etnohistoria, arqueología, estudios de traducción) en el que se inserta este trabajo tiene como uno de sus objetivos la identificación de sitios de explotación del oro desde Concepción hacia el sur, en la línea de los estudios arqueológicos que sugieren una posible explotación incaica e incluso preincaica, y a contrapelo de una historiografía clásica según la cual los incas no pasaron el Biobío. En este marco general, y sin olvidar que el mapudungun se hablaba en el siglo XVI en un territorio mucho mayor que el de la Araucanía que abarca el proyecto, indagamos, desde la lingüística histórica y con una mirada traductológica acerca de la significativa presencia de la palabra milla (oro) en mapudungun, y su lugar relativo en la sociedad mapuche, sociedad que, según los registros, no parece haber concedido a este metal la importancia material y simbólica que tuvo en las culturas andinas. Para ello, realizamos en este trabajo una revisión del estado de la cuestión, y sistematizamos los datos lingüísticos que proporcionan diversas fuentes, primarias y secundarias, desde el siglo XVI al $\mathrm{XX}$, despejando en la medida de lo posible las incógnitas en torno al origen de la palabra milla y el significado cultural del oro en la sociedad mapuche.

Palabras clave: cultura mapuche, lingüística histórica, traductología, mapudungun, léxico metalúrgico, oro. 


\begin{abstract}
This paper is part of an interdisciplinary project (ethnohistory, archaeology, translation studies) of which one of the objectives is the identification of gold extracting sites south of the city of Concepción. It develops the hypothesis, put forward by archaeological studies, of possible gold mining by the Incas or even earlier, as opposed to an historiographical theory which claims that the Incas did not cross the Biobio river. Against this background, and considering that in the sixteenth century Mapudungun was spoken in a much larger area than the one covered by our project, i.e. Araucania, we inquire on the conspicuous presence of the word milla (gold) in Mapudungun, and the extent of its significance in mapuche society, a society that, according to records, does not seem to have given gold the symbolic and material importance it had in Andean cultures. Through a historical linguistics and translation studies approach, we undertake a review of the state of the question and systematize linguistic data provided by primary and secondary sources, from the sixteenth to the twentieth century, in an attempt to resolve, as much as possible, the uncertainties surrounding the word milla and the cultural significance of gold in mapuche society.
\end{abstract}

Keywords: mapuche culture, historical linguistics, translation studies, mapudungun, lexicon of metallurgy, gold.

Recibido: 13 junio 2020. Aceptado: 15 noviembre 2020 


\section{Introducción}

Las lenguas se modifican por dinámicas internas, intralingüísticas, y por contacto interlingüístico, y el estudio de estos procesos es materia de la lingüística histórica. Coadyuvan a ella, según sean los objetos de estudio, la lexicografía, la semántica histórica, y la socio o etnolingüística con sus correspondientes abordajes, métodos y preguntas. Por su parte, los estudios de traducción o traductología, y en particular su vertiente sociohistórica, favorecen la investigación de los intereses y las voluntades que subyacen a los cambios lingüísticos en sociedades en contacto, voluntades o predisposiciones colectivas, que pueden ser histórica o culturalmente identificables.

En este trabajo, el enfoque lingüístico-traductológico trata, pues, de complementar las perspectivas antropológicas y arqueológicas del equipo de investigación del proyecto, como hemos hecho en proyectos de investigación anteriores (Payàs, Zavala y Curivil, 2015; Zavala, Dillehay y Payàs, 2020), para tratar de iluminar aspectos particulares de las dinámicas interétnicas al introducir la reflexión acerca de cómo la relación colonial produce cambios en los usos lingüísticos.

El oro fue el motor de la conquista de América: su búsqueda motivó las empresas coloniales y fue el mismo oro el que permitió financiarlas y expandir su influencia a otras áreas de actividad económica. En el plano simbólico-discursivo, encontramos el oro, con sus propiedades materiales y sus connotaciones míticas, en la producción de discurso sagrado y la literatura colonial. Tanto el oro como las minas o lavaderos desde los cuales se extraía tuvieron su lugar en la retórica cristiana en América, en tanto signo de la gratitud divina por la fe y el compromiso evangelizador de los monarcas y sus agentes (Gutiérrez Merino, 1990). En el caso inca, coincidieron en su aprecio por el oro conquistadores y conquistados, pues la sociedad indígena le dio a este metal un lugar prominente en el universo de lo sagrado y, por lo tanto, en el poder y la jerarquía. Como sociedades metalúrgicas, las andinas tuvieron nombre propio para el oro (quechua: quri, aymara: chuqi).

Aunque las excavaciones arqueológicas han arrojado algunos vestigios, datándolos hacia el año 1000 DC (Munita et al., 2009), no han sido suficientes como para postular una actividad, siquiera medianamente intensa, de extracción y trabajo de metales, que haya podido reflejarse en usos lingüísticos. Debe considerarse, por lo tanto, que la sociedad mapuche no fue propiamente una sociedad metalúrgica. Fue obligada a extraer el oro y otros minerales, primero por los incas, y luego por los españoles, y no parece haber adoptado de ellos el afán por obtenerlo y emplearlo. Independientemente de algunas referencias en las crónicas coloniales, que deben tomarse con cautela, la historiografía y la antropología no registran que haya habido de parte de los mapuche un interés particular por el oro (aunque está en la naturaleza, es visible y puede extraerse con poca tecnología). Como es patente en las fuentes del XIX, cuando pudo manifestarse interés, este se decantó por la plata y no por el oro, muy probablemente por ser más común y asequible: la platería mapuche que hoy se conoce es, sobre todo, de origen colonial, a base de monedas espańolas recicladas, y no parece haberse desarrollado orfebrería de oro.

Por lo tanto, si, como se ha supuesto, la sociedad mapuche no explotó el oro por su cuenta o no tenía aprecio por él, debería haber adoptado la palabra de una de las lenguas de las sociedades que usaron la mano de obra mapuche para explotarlo, o sea, del quechua o del castellano. Sin embargo, nada permite por ahora sostener esta hipótesis ni afirmar que la palabra mapuche 
para oro provenga de otra lengua. Nuestras indagaciones nos hacen concluir por ahora que milla $^{1}$ no proviene de ninguna de las lenguas con las que el mapudungun ha tenido contacto. No se encuentra como tal ni como radical en las lenguas andinas. ${ }^{2}$ No parece tampoco traducción de significados de otras lenguas. En cuanto a los documentos consultados, la palabra milla aparece en distintos corpus: como unidad independiente, cuando significa oro, y como radical en la toponimia y onomástica, siempre con el significado de oro como metal o con el de alguna de sus características físicas (color, brillo) o simbólicas (valor). Las referencias encontradas en el corpus del mapudungun colonial (sean o no misionales) registran siempre milla, mientras que aquellas posteriores al siglo XIX registran alguna alternancia entre la palabra mapuche milla y el préstamo oro.

La principal actividad minera en Chile, desde la llegada de los españoles, fue la del oro; se hizo explotando los lugares ya trabajados para el tributo al Inka y buscando nuevos yacimientos. Se usó, como en el caso inca, mano de obra local, en buena parte mapuche-hablante, que, por contacto, y siempre en el supuesto de no tener nombres propios, tuvo que adquirir los vocablos para denominar los metales, los objetos y las actividades relacionadas con la extracción, transporte y procesamiento. Nos preguntamos, entonces, cómo se construyó la inteligibilidad mutua del concepto de oro, incluidos sus significados simbólicos y, atendiendo a esta pregunta, expondremos, sobre la base de una amplia selección de fuentes, las posibles valoraciones que el oro tuvo o pudo tener desde perspectivas mapuche y no mapuche en distintas épocas, haciendo hincapié en cómo se procesó lingüísticamente la incorporación de metales nuevos en la cultura mapuche, y contextualizando el caso con el de otras sociedades del subcontinente que fueron obligadas por los incas o por los españoles a extraer metales. Por último, recogiendo las conclusiones preliminares de estos abordajes y con el aporte de la memoria oral y del kimün, conocimiento mapuche, sugeriremos una posible explicación de carácter antropológico al presunto desinterés de la sociedad mapuche por el oro.

Como sucede con otros aspectos de la cultura indígena cuyo estudio se pretende, la escasez de fuentes directas condiciona las decisiones sobre el corpus documental que puede contribuir a su conocimiento. En este caso hemos preferido efectuar un amplio barrido de fuentes en las que el oro resulta mencionado o explicado, fijándonos especialmente en las que pueden proporcionar vislumbres sobre su estatus cultural en la cultura mapuche y cómo este estatus pudo cambiar a raíz de las condiciones coloniales.

\section{Valoraciones del oro en el contacto mapuche-hispano}

Exploramos a continuación la manera en que se entendió el oro en las dos sociedades en contacto. Tratándose de una búsqueda en el imaginario pasado para la que solo hay fuentes del lado espańol, no pretendemos dar un valor de verdad absoluta a las mismas, razón por la cual preferimos hablar de perspectivas y valoraciones sugeridas por estas.

1 En este trabajo usamos el Alfabeto Mapuche Unificado (AMU) para escribir el mapudungun; para reproducir el mapudungun en otras fuentes respetamos la grafía original.

2 Agradecemos a los lingüistas Willem Adelaar, Rodolfo M. Cerrón-Palomino, Matthias Pache y Andrés Salanova sus orientaciones al respecto en diversas comunicaciones por correo electrónico. Asimismo, agradecemos a la lingüista mapuche María Catrileo y al experto de la cultura mapuche, don Florencio Manquilef, en comunicación personal, sus indicaciones y confirmación de la percepción común actual mapuche sobre el oro. No obstante, liberamos a todos ellos de cualquier responsabilidad por las afirmaciones que hacemos en este artículo. 


\section{Desde una perspectiva no mapuche}

\section{Según las crónicas coloniales}

Como lo atestiguan los primeros contactos descritos en las crónicas, los dignatarios mapuches llevaban adornos de oro, si bien no se refiere nada parecido a lo que los españoles encontraron en el Perú. Transcribimos a continuación algunas de las citas. La primera proviene del glosario que antecede el poema La Araucana ("Declaracion de vocablos escuros"), y las siguientes son extractos de crónicas coloniales recogidas ya por Inostroza (2010) en su trabajo sobre la economía mapuche colonial:

Llauto. Es un trocho o rodete redondo, ancho de dos dedos, que ponen en la frente y les ciñe la cabeza: son labrados de oro y chaquira con muchas piedras y dijes en ellos, en los cuales asientan las plumas o penachos de que ellos son muy amigos (Ercilla, 1776 [1574], p. XLIX).

Traen brazeletes de oro y de plata y una manera de coronas. Traen al pescuezo una manera de diadema y de turquezas y de tiritas de oro a manera de estampas. Ellas andan como las del Mapocho, salvo que traen una manera de zarcillos de cobre (Vivar,1966 [1558], p. 180).

Fuera destas mujeres que se casan, hay otras muchas que tienen por oficio salir en los días de banquetes a estos bebederos a ganar, como hacen en Europa las meretrices, que llaman rameras, y para esto se engalanan con los más ricos atavíos, usando también de collares, zarcillos y otras joyas de oro con piedras preciosas (Marińo de Lobera, 1865 [1595], p. 125).

Fui desde la ciudad de Valdivia, hasta cuyos términos han llegado los españoles, a descubrir la tierra que dicen los Coronados y anduve por ella adentro once o doce jornadas, en que hallé treinta o cuarenta mil indios de la manera de los de atrás, bien vestidos y con zarcillos y otros arreos de oro fino y de oro sobre plata y mucho ganado y sementeras, hasta que fui a dar a un lago grande, con mucha cantidad de islas que hay en el... (Hurtado de Mendoza, [1558] 18881902, p. 158).

Todas estas fuentes de mediados y fines del siglo XVI refieren la existencia de oro ornamental entre los mapuche del sur. Otras fuentes, de entrado el siglo XVII, lo desmienten. Y si aquellas pueden haber sido fantasiosas o erróneas, estas tienen como distintivo el hecho de asociar la falta de aprecio por el oro con la barbarie y la ignorancia. Dice el agustino fray Antonio de la Calancha, que publica en 1638 una historia de la Orden agustina en Perú, que los indígenas de Chile "[N]o estiman ni el oro ni la plata, ni tienen rito, adoración ni culto" (citado en Medina, 1882, p. 14), y González de Nájera, en Desengaño y reparo de las guerras de Chile (ca. 1614), observa que llevaban piedras perforadas y otros abalorios: "Estas dos maneras de joyas son las piedras preciosas i el oro de los indios" (citado en Medina, 1882, p. 171).

Y, sin embargo, algún sentido debía tener el oro, pues en medio del fantasioso relato que recoge López de Gómara en su Historia de las Indias, y que atribuye a soldados que iban con Pedro de Valdivia, aparece el nombre de una "reina de amazonas": Guanomilla, que, dice 
textualmente, "suena cielo de oro, de donde arguyen muchos... ser tierra mui rica" (Medina, 1882, p. 116).

No parece, pues, concluyente la información que proporcionan las crónicas; sin embargo, el antropónimo Guanomilla y su significado (wenu= espacio de arriba, cielo; milla $=$ oro) están correctamente registrados por López de Gómara en su crónica de mediados del siglo XVI, y, como apellido, Huenumilla existe en la actualidad. El hecho de que se atribuya ese nombre a una "reina" podría hacernos suponer que el oro tenía atributos de nobleza.

José Toribio Medina considera, sin entrar en discusión, que los indígenas (sin especificar etnia ni lugar) tenían ornamentos y objetos de oro, pero que rápidamente fueron a parar a manos de los españoles, y de ahí que el oro haya desaparecido de circulación:

Los españoles de la conquista, que, como se sabe, se manifestaron insaciables buscadores de oro, no tardaron en descubrir que los sepulcros indíjenas contenían por lo jeneral joyas i otros objetos del precioso metal, i desde aquella misma época comenzaron las escavaciones. Todo lo que se hallaba se vendía por su peso o se fundía (Medina, 1882, p. 262).

Esto nos lleva a preguntarnos de qué manera los mapuche pudieron haber respondido a la voracidad espańola. Desde luego, fue motivo de rebeliones y alzamientos, y tenemos como referencia temprana la crónica de Mariño de Lobera, donde se narra que a Pedro de Valdivia se le hizo beber "una olla de oro ardiendo" como escarmiento (Marińo de Lobera, [1595] 1865, p. 157). Y una vez establecida la frontera y suspendida la extracción, los mapuche no parecen haber querido saber más del oro. El abate Molina deja el siguiente testimonio:

En las provincias australes situadas entre el río Biobío y el archipiélago de Chiloé, se descubrieron antiguamente algunas minas de bellísimo oro, de las cuales sacaban los españoles sumas inmensas y para cuyo beneficio establecieron una casa de moneda de Valdivia y otra en Osorno: pero luego que los araucanos despojaron de aquellas tierras a los españoles con repetidos hechos de armas, cerraron aquellas minas enteramente, prohibiendo a toda clase de personas, bajo pena de la vida, el abrirlas de nuevo, porque aquel pueblo guerrero está muy distante de hacer el aprecio que hacemos nosotros de este ídolo adorado de la avaricia (Molina, 2016 [1788], p. 91).

Este ocultamiento del oro está también tematizado en uno de los mitos recogidos por Bertha Koessler-Ilg en la zona del Lácar en épocas modernas: "el oro que los indios saben dónde se encuentra, en ricos yacimientos que sus sacerdotes les ordenaron luego ocultar, tapando las minas con piedras, provocando derrumbamientos...” (Koessler-Ilg, 1954, p. 87).

Tanto la crónica de Molina como el mito recogido por Koessler-Ilg hacen hincapié, además, en el hecho de que se prohíbe volver a tocar el oro ("bajo pena de vida", dice Molina; "sus sacerdotes les ordenaron", dice Koessler), es decir que no solo se reacciona activamente, tomando providencias concretas como la de esconderlo, sino también en el plano simbólico: haciendo tabú del oro. Volveremos más adelante a ello. 


\section{Según la retórica cristiana}

Los tesoros de América fueron entendidos como parte del plan divino del que los españoles se hicieron instrumento. Teológicamente se sostuvo que el hecho de que hubiera tanta riqueza en manos de bárbaros e infieles era una muestra del amor de Dios, que de esta manera premiaba a los cristianos que luchaban por la fe (Gutiérrez Merino, 1990). En la retórica sagrada se usaron analogías y metáforas relativas a que el oro, metales y piedras preciosas eran el tesoro escondido de la religión, Dios aparecía personificado como orfebre, el cristiano como minero, el resplandor de los metales representaba la fe encendida, etcétera.

Si bien el oro y la plata tuvieron un lugar en la sermonaria colonial, no sabemos si estos sermones fueron empleados en la evangelización indígena chilena. Curiosamente, en los únicos ejemplos que conocemos de sermones en mapudungun, o sea, para indígenas, el oro se menciona como objeto despreciable, lo que nos hace pensar que circuló un doble discurso, que reforzaba el aprecio del oro en los españoles, y su desdén en los indígenas. Los sermones a que nos referimos son los del P. Luis de Valdivia (1897 [1621]), textos bilingües castellanomapudungun, con las dos versiones en la misma página, que nos permiten cotejar el sentido en ambas lenguas. Valdivia traduce como milla ese oro connotado idolátricamente, de manera que extiende el significado presunto de milla añadiendo una connotación negativa, desde luego inexistente en el mapudungun si pensamos en Guanomilla, la "reina de amazonas". Véanse a continuación los extractos de los sermones séptimo y octavo del Sermón en Lengua de Chile, del jesuita Luis de Valdivia, donde se da el equivalente oro= milla:

Veychi puche quidù Dios vfchi-buygn, mùpiltubuign cay, vill caque che ape ta vill maputupuche coilla gechi Dios ta vf-chibuygn, ta huell antù, huel cùyen, huell mamùll meu pañillihue meu milla meu ta ñi vemel chi che ta vfchiuygn ta genoquimche buy pu ve.

Estos adoraban a solo Dios, y en él creían todos, casi los demás hombres del mundo adoraban dioses falsos, unos al Sol, otros la Luna, otros, hechuras de sus manos, a hombres de madera, hierro o oro, eran hombres sin conocimiento (Valdivia, 1897 [1621], p. 56; el destacado es nuestro).

Vey ta ñi pu imagen ta huyricanmagequlu ta ñi ad egn mgelu ta niebijn, veychi pu imagen cay vachi cùme que pu santo duamtulcaqueeyn meu vey meu cay ta veychi pu imagen cay ta raquiquebijn, ta vey egn meu ta pu santo ta vfchiquebijn cay. Huyricagequelu pu santo ta mamùll meu rume, ta quillcameu, ta lien meu,milla meu chey rume: huelu inchiñ raquiquelabijn ta mamùll, ta milla, ta quillca, vill tva raquivalnolu, niten pu santo veychi mamùll meu ùyriangequelu, ...

Todos estos santos que os he contado, están ahora en el cielo con gran gozo viendo a Dios, y allá le ruegan por nosotros. Y por esto a todos ellos los honramos, y llamamos, para que rueguen por nosotros, y cuando nos bautizan nos ponen sus nombres, y somos ellos, y nosotros de un nombre, y a sus imágenes (que suelen ser pintados al modo que fueron sus figuras) las tenemos, y ellas nos hacen acordar de los santos, y por eso a las mismas imágenes las veneramos, porque en ellas adoramos los santos. Y aunque están pintados en madera, o en papel, o plata, o oro: pero no adoramos la madera, ni la plata, ni oro, ni papel, que nada de eso es para respetar,... (Valdivia, 1897 [1621], p. 65; el destacado es nuestro). 
En estos dos ejemplos se percibe la complejidad de tachar, por una parte, de idolátrico el oro con el que se fabricaban las deidades (alusión al becerro de oro bíblico, pero tal vez también al oro inca) y, por la otra, convencer de que era aceptable cuando se trataba de santos, con lo que había que precisar que se adora la figura pero no la materia de que está hecha. Lamentablemente no tenemos otras fuentes de estas características hasta el siglo XIX o principios del XX, y aun sin haber hecho una exploración exhaustiva de todas ellas, las que hemos consultado refieren siempre milla como equivalente de oro (material o simbólico). He aquí unos fragmentos del Compendio de Historia Sagrada / Nidolke daりu Dios ñi Nùtram de Félix de Augusta, texto monolingüe en mapudungun, que es traducción de una obra alemana:

Feimeu nentui Faraón kiñe iwel-kuq ñi kuq meu ka takukanofi Kose ñi kuq meu ka kal.kaitzkukanulelfi milla kadena ñi pel. meu (Augusta, 1907, p. 21).

Mayordomo dipufi feichi pu peñiwen ka elupufi dəyu ñi fei pieteu Kose. Feyeyn lloudayuinn: Chumyelu kam weñeafuiñ plata kam milla chi ñi ruka meu tami patron? (Augusta, 1907, p. 26).

Feimeu lukunaqpuign ka adorafign, ka witrakanulpafinn milla, incienso ka mirra, ki uke yẹn ñi duamtufiùm pichi Kesús (Augusta, 1907, p. 51; los destacados son nuestros).

[Entonces el faraón sacó un anillo de su mano y lo puso en la mano de José y también le colgó una cadena de oro en su cuello (Augusta, 1907, p. 21).

El mayordomo llegó hasta el lugar donde estaban esos hermanos y fue a darle la palabra a José. Ellos respondieron: ¿Cómo podíamos robar plata o tal vez oro de la casa de tu patrón? (Augusta, 1907, p. 26).

Entonces llegaron a arrodillarse y lo adoraron. También le fueron a dejar oro, incienso y mirra, hacía mucho tiempo que esperaban al pequeño Jesús] (Augusta, 1907, p. 51; la traducción es de Fresia Loncón).

En la letra del canto religioso "Un Dios por galardón”, está claro el significado peyorativo de milla= oro: "Iñ Dios mi wewagel: lloftukeley wekufü, fey milla ngey ñi lashu, ñi nüpüllipeyüm. Nuestro Dios será tu premio, acechando está el demonio; su lazo es de oro, con que coge las almas" (Augusta, 1910, pp. 220-1).

Podríamos postular, entonces, que, desde la perspectiva hispana y en el período colonial y republicano, milla se considera equivalente de oro como metal, y que es el género religioso de carácter evangelizador el que, por un procedimiento de extensión del significado (Parodi, 2005), induce una nueva acepción, la de metal despreciable, ligado al pecado.

\section{El oro desde la perspectiva mapuche}

\section{Según textos tradicionales mapuches}

Si bien en las crónicas y documentos coloniales no religiosos, como las actas de parlamentos hispano-mapuche, o en Pineda y Bascuñán, se pueden encontrar transcritos, y en castellano, 
algunos ejemplos de discurso indígena, nada nos dicen del sentido que puede haber tenido el oro para la cultura mapuche. En cambio, en registros de géneros rituales mapuche tardíos, recogidos por los estudiosos del XIX-XX, y hasta la actualidad, milla figura no solo como metal sino con atributos simbólicos, positivos, ligados a la cosmovisión. Así, pues, tenemos milla= oro en contextos de koyag o kawiñ (asamblea, conferencia, parlamento) o ngillatun (rogativa) tanto del lado chileno como argentino, con los siguientes sentidos:

\section{a) El piso, suelo o pampa de oro, lugar sagrado}

La palabra tafü parece tener un sentido no especializado, de "suelo de la casa", según Augusta, pero son significativos para nosotras los sentidos que el autor vincula a la cosmovisión: milla tafü= 'suelo de oro', el lugar donde habla el wewpife (orador) o donde se lleva a cabo la asamblea o parlamento: "Sobre el suelo de oro, dicen, parlamentó, dicen, Quintrequeupu, el finado" (Milla tafü mew, piam, wewpikay, piam, Quintrequeupu yem) (Augusta, 1934, p. 236). Asimismo, en su diccionario, Augusta señala que los tafü son "cuevas imaginarias debajo de la tierra donde, según creencia antigua, los hechiceros se forman y habitan" (Augusta, 1916a, p. 213). El concepto tafü en asociación con milla parece, pues, arraigado en la espiritualidad ancestral, como nos lo sugiere el kimche, sabio de la cultura mapuche, don Florencio Manquilef (F. Manquilef, com. pers., 19 de octubre 2019).

La noción de un piso, campo o suelo de oro sobre el cual se efectúan las ceremonias es confirmada también por W. Hassler, relatando un ngillatun al que asistió en 1953 en la zona del Lácar: "Como no tienen templos, hacen su rogativa en milla lelfün (pampa de oro)" (Hassler, 2014, p. 73) y, en el "Diálogo del Hualoncokuel", registrado en épocas más recientes por Tom Dillehay de boca de algunas machi de la zona de Lumaco, se registran varias ocurrencias de milla lelfün, relacionadas siempre con el espacio sagrado de los promontorios sagrados llamados kuel (Dillehay, 2007, pp. 412-47).

Conviene señalar que en algunas partes el ngillatun se efectúa sobre un pillan lelfün (Pillan= entidad espiritual superior) (Golluscio, 2009, p. 72). El hecho de que en algunas fuentes el terreno o suelo sobre el que se celebra el ritual sea "de oro" y en otras "del pillan" (a menos que haya habido confusión por homofonía u otra razón en las transcripciones: milla/pillan) parece indicar una asociación entre milla y el mundo espiritual, cosa que se confirma en la invocación a un "Milla Kalkin" (kalkin= águila) en el mismo relato de ngillatun reproducido por Hassler:

El cacique, después de almorzar, se dirige a los asistentes: "Puchai Ngillatun entuaein rüngui, chali amutuaien lafquen meu, tucumeaien rüngui con llanca piuke lafquen" (Terminó la rogativa, sacaremos las cañas, iremos a saludar al lago; entregaremos las cańas con el santo corazón al lago). Todo es recibido por Milla Kalkin (espíritu del agua) (Hassler, 2014, pp. 78-9, el destacado es nuestro).

\section{b) La casa de oro}

En los ngillatun, la expresión "casa de oro" también era y es recurrente. Así figura en esta rogativa referida a Félix de Augusta por su colaborador e informante principal, Pascual Segundo Painemilla: “'Küme mongelepe ñi pu cordaro' piaymi, Rey Fücha, Rey Kuche, anüleymi tami milla ruka mew”, con su traducción: “'Que vivan bien mis corderos', dirás (por nosotros), Rey anciano, Anciana reina, que estabas sentado en tu casa de oro" (Augusta, 1910, p. 6, los destacados son nuestros). Augusta recoge luego milla ruka= 'casa de oro' en su diccionario (Augusta, 1916a, p. 139), posiblemente a raíz del relato anterior (cf. Latcham, 1924, p. 272). También 
en el "Diálogo del Hualoncokuel”, registrado por Dillehay, la machi Juanita, de Rucalleco, al realizar sus oraciones para "curar" un kuel considerado enfermo (Hualonkokuel, nombre asociado al maíz, wa, y a un lonko, o cabeza de linaje, según el autor) habla de su milla ruka (Dillehay, 2007, p. 424). Dillehay plantea que las y los machi se relacionan estrechamente con los kuel, desde cuya cima realizan distintos rituales para comunicar con las deidades y espíritus ancestrales del wenumapu (Dillehay, 2007, p. 225).

\section{c) Otras referencias en contexto sagrado.}

Fuera de los casos más referenciados de la casa o el suelo de oro, hemos encontrado numerosas ocurrencias de milla en los dos textos rituales de machi transcritos por Dillehay: el del Hualoncokuel, antes mencionado, y el del Tren Trenkuel, el kuel donde reside Tren Tren, la serpiente benigna de los orígenes, el más poderoso del valle de Lumaco (Dillehay, 2007, pp. 412-64). Salvo en tres casos, en que aparece la palabra sola referida al oro como metal, se presenta en posición prenuclear, como adjetivo. En ocho ocasiones el rewe (tronco con escalones tallados, de donde toma su energía sanadora la machi) recibe el nombre de milla kalera (escalera), y también llevan el calificativo milla los préstamos bandera, kuchillu (cuchillo), stipu (estribo) y palabras autóctonas como paliwe (cancha de palín), pütrem (tabaco), rayen (flor), relmu (arco iris), perkin (penacho), fotüm (hijo), muday (chicha), kako (maíz molido), kuel (promontorio sagrado), foye (canelo), rewe (tronco ceremonial), angkacharu (vasija), y en expresiones como millaseña (señal de oro) y millawingka (forastero de oro). Esta ubicuidad en textos de tal naturaleza confirma la asociación del oro al lenguaje de lo sagrado y, en particular, a ofrendas y objetos relativos a los promontorios sagrados, los kuel. Milla estaría, entonces, asociado a los contextos rituales de mayor exclusividad indígena.

Hemos explorado también los textos pertenecientes a géneros tradicionales mapuche recogidos por Lenz en Estudios Araucanos: en "La queja de la viuda" figura milla (Lenz, 1897, p. 403), mientras que en "El pollo de oro" y "Huenchumir, el hijo del oso" (Huenchumir= wentrumilla, hombre de oro) se emplea oro, como préstamo (Lenz, 1897, pp. 201, 403). También se da este préstamo en los que Lenz señala que son de procedencia europea: "Los tres hermanos" y "Las tres señas" (Lenz, 1897, pp. 283, 304).

\section{Según la mitología}

No está documentado ningún mito propio de la cultura mapuche que tenga relación con el oro. En su compilación de mitos chilenos, Montecino (2015) proporciona en la entrada 'Oro' algunas generalidades (relación sol= oro; plata= luna) y ejemplos tomados de los relatos de Koessler-Ilg y de otras colecciones. Los ngen, o seres espirituales, como Millalonko (ver también Augusta, 1916a, pp. 139-40; Millalonko como wekufü o demonio), Millalobo y Millacol, que se describen en esta colección, están asociados a entidades caracterizadas como temibles o negativas, de cabellera o pelaje brillante o dorado, y no al oro como metal.

En general los mitos que describen el oro como riqueza provienen de otras tradiciones, sea directamente de Europa, sea de Europa vía Perú, o son de matriz andina, como los que registra Tangol en Chiloé. Es el caso del carbunco (o carbúnculo), un ser que custodia los metales y tesoros ocultos bajo tierra:

Este animalito cuyo pelaje brilla como el diamante, toma el color del metal que custodia. Si es una mina de oro, el pelaje es rojo; si es de plata, blanco. Cuando se 
hace presente, emerge súbitamente desde el interior de la tierra y muy luego desaparece corriendo con la velocidad del rayo. Los buscadores de tesoros lo acechan para lanzarle un cinturón, una faja o un pañuelo. El que consigue hacerlo, verá que el Carbúnculo se apodera del objeto y luego desaparece. El afortunado saldrá al día siguiente a recorrer la comarca y donde encuentre la prenda que lanzó al carbúnculo, ahí debe cavar para desenterrarlo (Tangol, 1976, pp. 114-15).

En Perú se encuentra también este personaje, y según Gentile (2007), que documenta su presencia en el virreinato, es de tradición medieval europea.

Otro mito o leyenda de los registrados por Tangol es "La Curamilla" (Tangol, 1976, pp. 11920). Este es el nombre que se da a una gran roca de oro macizo que, según el relato, surge del fondo de una laguna al sur del villorrio de Cucao. De esa laguna nace un río que antiguamente conducía a una caverna, en la que habitaba una hermosa joven que, al llamado del enamorado, salía a posarse sobre la roca de oro. Las similitudes con relatos europeos de sirenas hacen de este mito una posible derivación.

Menos cercanos a las posibles tradiciones europeas son los mitos recogidos por Koessler-Ilg en la zona del Lácar (Koessler-Ilg, 1954). Uno de ellos es el del "Monstruo de la bosta de oro o el bien peinado". Se trata de un curioso relato sobre este personaje, el "bien peinado", que arroja pepitas de oro como excremento. El relato de "La puerta de oro del príncipe de los Incas" se refiere al oro como tributo al Inka. Trata de una cadena de este metal que se confecciona como regalo al Inka, y que por su tamaño la llaman 'puerta de oro'. Para protegerla de la codicia de los españoles, los indios la ocultan y la echan en la boca del volcán ardiendo, como ofrecimiento al pillan.

El origen y circulación de elementos cosmovisionarios y mitos presentes en el sur de Chile ha sido materia de estudios recientes. Desde los estudios discursivo-literarios, Ajens (2017) ha estudiado la presencia en zona huilliche del mito del Inkarri, y postula el contacto posible entre esta zona y el Tawantinsuyu, las posibilidades de intertextualidad rastreable o de existencia de una matriz cosmovisionaria subyacente (también se recogen relatos del Inkarri en Purén y Lumaco, al noroeste de la Araucanía, con lo que se amplía el ámbito de influencia). Constantino Contreras sugirió a su vez que podían haber circulado mitos como este entre Lima y Chiloé cuando el archipiélago pasó a depender del Virreinato, a partir de 1767 (Contreras, 1991, pp. 14-32). Dillehay y Gordon (1998) atribuyen a la actividad de los lavaderos de oro la circulación de mitos y relatos, mientras que otros autores apuntan a una transmisión por vía de los indígenas peruanos (yanaconas) que llegaron con el ejército español en el siglo XVI. Por último, no hay que descartar la vía moral-pedagógica de toda actividad misionera (relatos cristianos adaptados a realidades indígenas, o relatos autóctonos moralizados, como en el caso del mito del Inkarri, con la moraleja del castigo a Pizarro).

Sintetizando este repaso, es posible, entonces, que a las nociones y valoraciones autóctonas se hayan superpuesto las nociones impuestas por el contacto, aunque resulta difícil, en el estado actual de los estudios, y por limitaciones de distinto orden, poder decir si esta circulación, a base de traducciones o reformulaciones, incidió en la percepción local sobre el oro y en los usos lingüísticos asociados. Trataremos a continuación de presentar otros tipos de fuentes que creemos pueden resultar más fácilmente productivas: las de los ámbitos de la toponimia y onomástica. 


\section{Según la toponimia}

Ante todo, es preciso reconocer la complejidad de los estudios de toponimia, de lo cual nos advierte con mucho acierto Cerrón Palomino (2015). Podemos decir por ahora que la toponimia de origen mapuche, muy extendida en Chile, es descriptiva, es decir, que se basa en la descripción de algún rasgo del lugar, $y$, aunque no es posible saber en qué momento se produjo la fijación léxica de la toponimia más antigua, llama la atención la presencia del radical milla que, en los repertorios clásicos, a saber, Solano Asta-Buruaga, Armengol Valenzuela, y Riso Patrón, se registra desde los 26 o 27 grados de latitud sur, relacionada casi siempre con auríferos. ${ }^{3}$ También es preciso advertir que en estos registros no siempre se refleja la toponimia llamada menor, y hemos encontrado en la documentación colonial y posterior otros nombres de lugares, o de unidades territoriales autóctonas con la partícula milla, que no figuran en ellos (Millatabu, por ejemplo, nombre de una reducción que figura en el listado de asistentes al parlamento de Tapihue de 1774, o Millanahuel, nombre de un rewe consignado por Latcham, como se verá más adelante).

El Glosario Etimológico de Armengol (Figura 1) anota con sus etimologías: "Arquemilla, cerros al poniente de Illapel, de arcun, secarse, y de milla, oro= oro seco" (Armengol, 1918, p. 46); "Cuimilahue, fundo de Calle-Calle, departamento de Valdivia, de cuyivi, antiguamente, y de millahue, mina de oro= antigua mina de oro" (Armengol, 1918, p. 175); "Curimilla, una comarca, y un antiguo guerrero de Tirúa, de curi, negro, y de milla, oro negro" (Armengol, 1918, p. 196). Registra también los siguientes:

Millahue (río tributario del Quilacoya, otro tributario del Choapa y paraje de Ancud)

Millahueico (paraje Temuco)

Millahuillin (Valdivia)

Millahuin (Villarrica)

Millai (cerros, Constitución)

Millaneco (Lebu)

Millañir (fundo Nacimiento)

Millapén (caserío Mulchén)

Pumillahue (San José de la Mariquina, Valdivia; y Ancud, Chiloé)

Milladomuche (quebrada, Angol)

Millapoa (comarca de Nacimiento, donde Óñez de Loyola fundó Millacoya.

Arroyo y valle)

Millaqui (río afluente del Renaico)

Millarapue (Nahuelbuta)

Millauquén

En el diccionario de Riso Patrón (1924) (Figura 2), que se considera ampliación del de Solano Asta-Buruaga (1867), se registran algunos que estaban en Armengol, con la misma u otra grafía, además de otros topónimos, con descripciones más o menos someras, y a veces con sus coordenadas geográficas, como lo reproducimos a continuación:

3 Es de señalar la variabilidad que exhibe la toponimia en cuanto a su grafía, que dificulta las identificaciones a simple vista. Aquí no podemos sino hacer un acercamiento prudente y muy preliminar, reconociendo las complejidades de estos estudios y la necesidad de realizar abordajes interdisciplinares. El reciente trabajo de Lydia Fossa (2019) sobre el sitio de Chuqikirau, en los Andes peruanos, en el que pone en diálogo lingüística histórica, arqueología, antropología e historia, es una buena muestra de ello. 


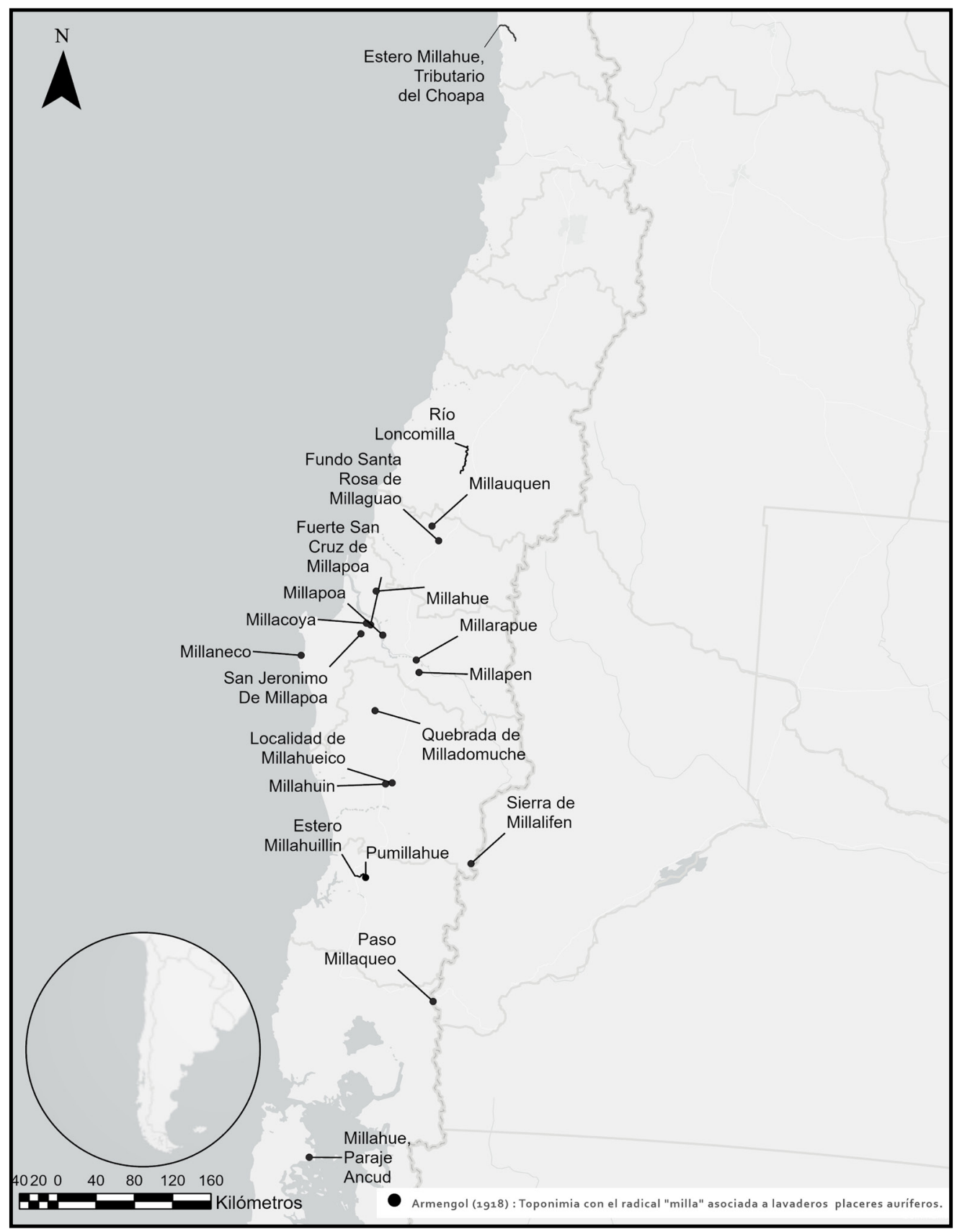

Figura 1. Toponimia con el radical milla asociada a lavaderos y placeres auríferos en el diccionario de Armengol (1918). Elaboración: Rodrigo Mendoza. 


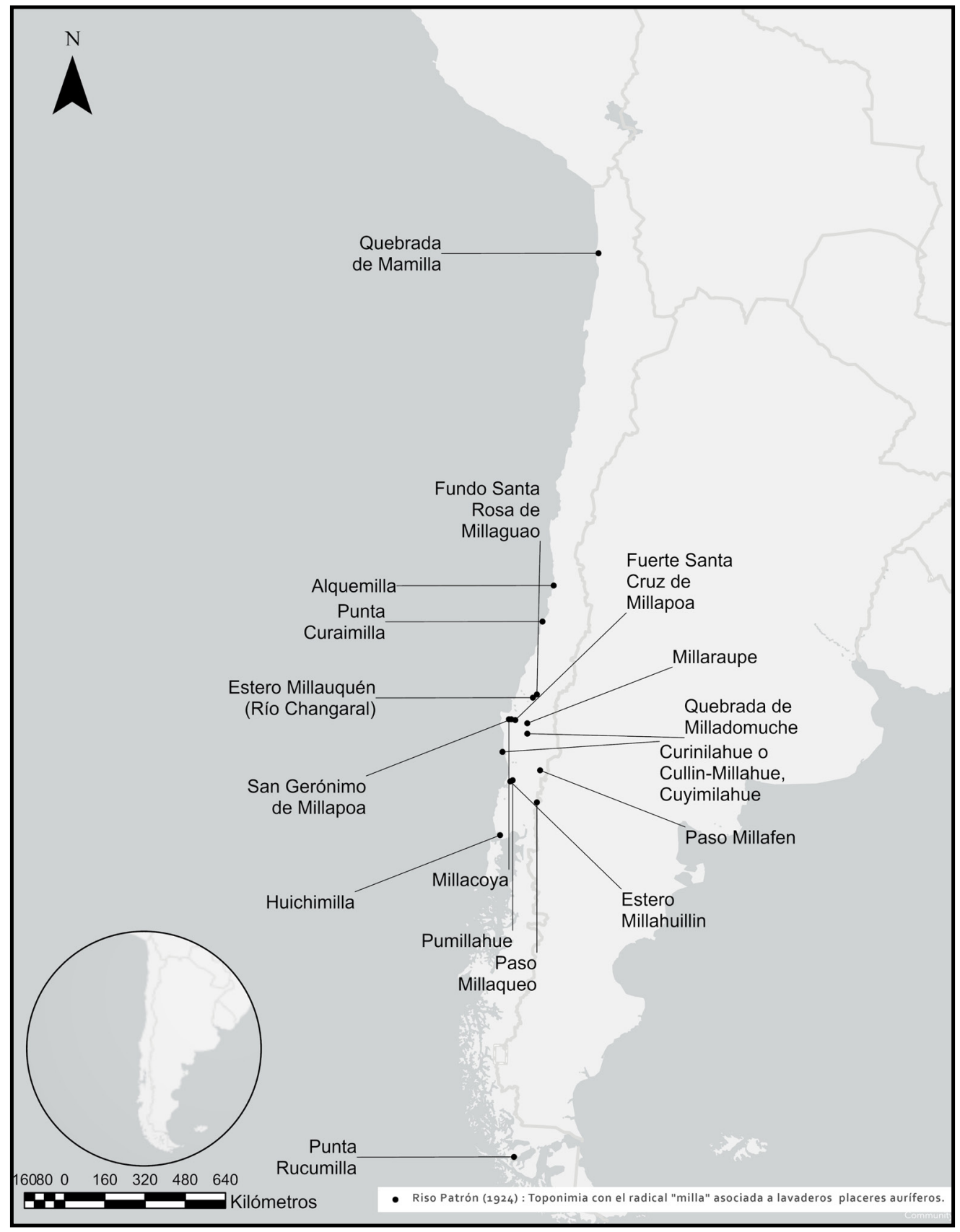

Figura 2. Toponimia con el radical milla asociada a lavaderos y placeres auríferos en el diccionario de Riso Patrón (1924). Elaboración: Rodrigo Mendoza. 
Millahuillin (carbón, cerca de Máfil)

Loncomilla o Longomilla (río) $33^{\circ}$

Alquemilla (cerro, oro) $31^{\circ}$

Millahue (río, arenas auríferas desde la conquista), también Miyague, Millague,

Mil-aguas, $31^{\circ}$

Millauquén

Coroumilla/ curaumilla (punta)

Curinilahue o Cullin-millahue, Cuyimilahue (estero) $40^{\circ}$

Huichamilla o Huichanilla (estero) $40^{\circ}$

Pumillahue (cerros) $31^{\circ}$

Mamilla (aguada, cerro) $21^{\circ}$

Millacoya (ciudad) $37^{\circ}$

Milladomuche (quebrada) $30^{\circ}$

Millaguao (fundo)

Millaquén (cerro)

Millalifén o Villalifen (sierra)

Millaneco (lugarejo), asiento minero carbón

Millangue

Millapoa (lugarejo) $37^{\circ}$

Millapué o Millapoa (comarca) $37^{\circ}$

Millarrepué o Millapoa (lugarejo), $37^{\circ}$

San Jerónimo de Millapoa (fortaleza) $35^{\circ}$, “construido en 1585"

Santa Cruz de Millapoa (fuerte)

Millaqueo (paso)

Millauquén (río) $36^{\circ}$

Pumillahue (caleta) célebre por el oro, costa oeste de Chiloé $41^{\circ}$

Rucumilla (punta) $53^{\circ}$

Si bien solo se podrían despejar las dudas haciendo un análisis caso por caso, y cotejando datos geográficos, históricos y arqueológicos, además de lingüísticos, nos parece revelador que varios lugares con milla sean ríos, esteros, quebradas o arroyos, lo que indicaría la posibilidad de que hubiera habido lavaderos. Otros nombres que se identifican con cerros o sierras podrían asimismo estar asociados a vetas o afloraciones del metal.

Por la importancia histórica de los lavaderos de Quilacoya, y su asociación geográfica con Millapoa o Millacoya, es preciso señalar el quechuismo qhuya (veta, mina) en la toponimia: "Los que adoraban los cerros dellos y las propias minas, que llamaban coya, pidiendo les diesen de su metal..." (Bernabé Cobo, citado en Olivari, 1994, p. 212). En Chile, Armengol registra el topónimo "Collas (cajón de): minas de plata, cobre y plomo del departamento de Curicó, plural español del vocablo quichua y aymará coya, mina, en el cual se ha substituido la y de la penúltima sílaba por 1l, por ultracorrección; o por error de llellista” (Armengol, 1918, p. 148). Si así fuera, Millacoya podría ser, entonces, producto del contacto mapudungun-quechua o aymara: mina o veta de oro.

4 Para Armengol, Curanilahue no tiene -milla: "Curanilahue, río y fundo de San José, departamento de Valdivia, río y mineral de Lebu, de cura, piedra, y de gilahue, (de gilan) vadear= vado de la piedra" (Armengol, 1918, p. 191). 
Según Gay (1845), que cita una fuente manuscrita no identificada, los topónimos Millapoa, Quilacoya y Millacoya estarían emparentados. Millacoya, dice, es fundación de Martín Ónez de Loyola, sobre el lugar de Millapoa, reemplazando - poa por -coya. Sin dar mayor explicación, Gay dice a continuación que Millacoya se convierte en "Guilacoya o Guilacoyan, el de las minas", introduciendo luego un segundo significado para coya: "pero aun estos nombres eternizan la memoria de la antigua Millacoya, o Princesa de oro, a quien en su viudez honró el rey con muchos premios y grandezas" (Gay, 1845, p. 212). Estos dos significados del supuestamente homófono coya se registran en los distintos vocabularios del quechua (González Holguín, 1989 [1608]; Anónimo (Blas Valera, 2014 [1586]) y aymara (Bertonio, 1612). ${ }^{5}$ En la asociación entre Millapoa y Millacoya le sigue Armengol: "Millapoa, comarca de Nacimiento, donde Oñez de Loyola fundó Millacoya” (Armengol, 1918, p. 61). Riso Patrón, que registra ambos topónimos, no los asocia entre sí, ni tampoco con Quilacoya: "Quilacoya: Minas. Son de oro, en lavaderos o placeres, fueron descubiertas en 1552 por Pedro de Valdivia. Se formó un asiento de minas en octubre de 1553..." (Riso Patrón, 1924, p. 734).

Es de señalar, finalmente, que en las actas de los parlamentos publicadas por José Manuel Zavala figuran los topónimos Quilacoya (Zavala, 2015, p. 41; en referencia al oro), Millapoa (Zavala, 2015, p. 56; lugar de una batalla que tuvo lugar en 1599), y, sin más datos, Millarague (posiblemente Millarewe, o rewe de oro) (Zavala, 2015, p. 79; con Millarapue y Millaraque, como posibles grafías alternativas). En las tablas de asistentes al parlamento de Tapihue, de 1774 (Payàs, 2018, p. 413), se nombra asimismo la reducción de Millatabu (posiblemente Millatafü, o suelo de oro).

De este conjunto de datos, que requieren ulterior procesamiento, se infiere la relación entre el oro y los lugares en que se extrajo, pero la ausencia de fuentes que permitan datar la toponimia no permite sino suponer provisionalmente que esos nombres ya existían antes de la presencia española. Algunas preguntas de cuya respuesta penden conclusiones más firmes son de carácter epistemológico: ¿cómo nombraban los mapuche los lugares?, ¿con qué referentes?, ¿son las unidades territoriales mapuche (lof, rewe, ayllarewe ${ }^{6}$ ) topónimos en el sentido de que indican un lugar físico, son denominaciones sin delimitación precisa, o están ligados a nombres de jefes o individuos principales del lugar (como sucede, para dar un ejemplo conocido, con los topónimos-antropónimos de origen hispano-chileno de Lo Prado, Lo Vásquez)? Por último, si bien la toponimia nos resulta suficientemente productiva para poder suponer que la sociedad mapuche nombró los lugares donde había oro, también es cierto que en algunos casos puede haber duda en la identificación de los morfemas que componen el vocablo. Serán necesarios análisis más especializados, que incluyan consideraciones dialectológicas, para dilucidar cada caso.

\section{Según la onomástica}

La palabra milla, y sus grafías alternativas - mily -mir, es ubicua en la antroponimia (masculina, lo que no debe tomarse como que no formara parte de la femenina, obviamente) desde que se tiene registro escrito, y sospechamos que está asociada a connotaciones positivas, de prestigio, tal vez relacionada con linajes de poder. Sin embargo, esta afirmación debe tomarse con toda

5 La confusión o ambigüedad de sentido entre 'mina' y 'princesa' proviene de la dificultad de representar gráficamente en quechua estas palabras en la documentación antigua, como nos lo advierte la lingüista Lydia Fossa (Lydia Fossa, com. pers., 16 de marzo 2020), a quien agradecemos la aclaración y las referencias.

6 Ricardo Latcham, en su listado de nombres de estas divisiones consigna el ayllarehue Llancamilla (chaquira de oro), y el levo Millanahuel (león de oro) (Latcham, 1924, p. 602). 
cautela por el obvio sesgo historiográfico que favorece el registro de las familias poderosas y porque, en realidad, sabemos poco de la estratigrafía social mapuche y su reflejo en la onomástica.

Existen algunas compilaciones conocidas para la onomástica actual: Eugenio Alcamán (2017), por ejemplo, da 137 nombres con este radical en la zona huilliche, y son de consulta obligada Augusta (1907) y Meyer Rusca (1952), pero prácticamente no hay estudios sobre onomástica antigua, que es la que nos puede ayudar a determinar el carácter patrimonial de la palabra milla. La primera mención que encontramos, y posiblemente de las primeras en las crónicas, es la de Guanomilla, la "reina de amazonas" nombrada por López de Gómara en su crónica de 1552, que nos permite afirmar que los nombres propios de personas que llevaban este radical estaban ya sin duda antes del contacto.

Fuentes de la Guerra de Arauco registran nombres de individuos con milla también a mediados del siglo XVI, y también en las mismas fechas los hay en los valles centrales, nombrados en las fuentes (Contreras Cruces, 2017). Ricardo Latcham, que se ocupa de rastrear los linajes tradicionales mapuche, o cüga, a partir de un repaso de crónicas, juicios, probanzas y otros documentos coloniales, señala que en el siglo XVI milla está entre los tótems (sic) más frecuentes en los siguientes territorios: valle del Mapocho, del Maipo al Maule, Itata, Arauco, Tucapel, Catiray y Valdivia (Latcham, 1924, p. 79). Nombres como Millacheuque y Hualtemilla figuran en su registro en ese siglo (Latcham, 1924, p. 82).

También nos hemos valido de los listados de asistentes que figuran en las actas de los parlamentos hispano-mapuche que, por la exhaustividad, la precisión con que muchas veces indican los lugares de procedencia, y el hecho de que registran, lógicamente, personajes preeminentes (caciques, en su mayoría), creemos pueden dar indicios de la existencia de linajes relacionados sea con el oro como metal sea como símbolo.

De unos tres mil nombres de caciques participantes en los parlamentos que se celebraron entre 1593 y 1803, son en total 174 los que tienen el radical milla. El más antiguo, Guamimilla, aparece en la serie de parlamentos de Quilacoya, Rere, Taruchina e Imperial, todos ellos de 1593 (Zavala, 2015, p. 41). Los parlamentos en los que están más concentrados son los de Yumbel (celebrado en 1692) (Zavala, 2015, p. 169), San Juan de Purén (ídem en 1698) (Zavala, 2015, p. 203), Tapihue (ídem en 1746) (Zavala, 2015, p. 247) y Negrete (ídem en 1803) (Zavala, 2015, p. 413), aunque debe señalarse que la documentación de estos parlamentos contiene más información sobre participantes que otras. La ubicación geográfica de los nombres resulta interesante, pues se encuentran en general concentrados en la zona de la cordillera de Nahuelbuta y región Lafquenche, mientras que es mucho menor la representación en las zonas del centro y cordillera, sin que podamos por ahora aventurar una opinión sobre esta distribución geográfica, aunque podría asociarse hipotéticamente a los lavaderos existentes en esa zona. Sin embargo, para ello deberíamos poder afirmar que existe relación entre nombres de lugares y nombres de individuos. Al respecto, Ricardo Latcham registra como nombres de levo (unidad territorial básica) dos denominaciones con milla (Latcham, 1924, pp. 599-600) que se encuentran también como antropónimos en los listados de caciques asistentes a parlamentos de la compilación de actas de Zavala: Millapoa y Millarapue o Millarupu. Tendría entonces razón Alonso de Ercilla (1776 [1574]) cuando dijo que los caciques "toman el nombre de los valles de los que son señores" (Ercilla, 1776 [1574], p. L). 
Varias dudas subsisten respecto al valor social y significado lingüístico que tiene la palabra milla en la onomástica. En primer lugar, se considera que el nombre mapuche consta de dos segmentos, el primero remite a una cualidad accesoria, y el segundo remite al linaje, o künga. Del listado de asistentes a los parlamentos que figura en la edición de Zavala, aproximadamente la mitad tiene milla como cualidad accesoria y la otra mitad tiene milla como nombre de linaje. Sobre sintaxis interna de los nombres compuestos en mapudungun, remitimos a Baker y Fasola (2009) y a Zúníiga (2014).

En segundo lugar, ¿en qué momento se pone el nombre, y en qué condiciones? (Catriquir y Durán, 1990; Foerster, 2010). La atribución de nombre propio de prestigio y no de linaje viene aquí a colación, pues nos llama la atención que Febrés mencione en su Arte de la Lengua General del Reyno de Chile a dos jesuitas a los que los mapuche dan nombre en mapudungun, y que en ambos casos el nombre contenga el radical milla: Columilla ('oro colorado', alias del P. Diego Amaya) (Febrés, 1765, p. 120) y Millaleuvu ('río de oro', alias de un padre jesuita no identificado) (Febrés, 1765, p. 146). Las asociaciones del oro con la religión pueden haber influido en estos casos si pensamos incluso en los ornamentos de la indumentaria u objetos de oro que pudieran tener en las misiones. Independientemente de cómo se dieron estos nombres, este dato corrobora lo que los antropólogos y estudiosos de la onomástica mapuche afirman acerca de la adjudicación de nombres propios y la práctica honorífica de adopción de nombres reputados como importantes.

Sintetizando los hallazgos de este breve repaso de fuentes, podemos inferir la existencia, al menos desde que hay registro, del nombre milla asociado a rituales, lugares de extracción y nombres de personas, es decir con connotaciones positivas y de prestigio. Con toda la cautela que exige el hecho de trabajar con fuentes poscontacto, el hecho de que la toponimia y la onomástica sean elementos de los más antiguos en el léxico de una lengua nos inclina a pensar que estamos ante una palabra del léxico patrimonial. Contribuirá a despejar esta hipótesis el siguiente análisis de los vocabularios bilingües para confirmar las equivalencias de traducción y determinar cuáles fueron las estrategias denominativas empleadas por el mapudungun para otros metales, sea que los conocieran, sea que los hayan conocido después del contacto.

\section{Equivalencias y estrategias denominativas para el oro y otros metales según las fuentes lexicográficas}

En la historia de la metalurgia americana no es mucha la atención prestada a los aspectos lingüísticos; es más, solo parece haberse estudiado para las sociedades americanas que habían desarrollado la metalurgia antes del contacto con los espańoles (Bellamy, 2018). Es en la lengua, no obstante, donde quedan fijados los sentidos que una sociedad da a sus actividades y producciones, y el caso de los metales es uno de ellos. A efectos de nuestro estudio conviene, por lo tanto, analizar, aventurando incluso algunas comparaciones, de qué manera la lengua generó denominaciones para metales nuevos y distinguió entre nuevos y conocidos. Kate Bellamy, en su investigación doctoral sobre este tema para las sociedades ubicadas en la región andina, la zona itsmo-colombiana y el oeste de México, identifica seis estrategias empleadas en la denominación de metales específicos y del término genérico 'metal', basadas en el uso de: i) nombres de colores, ii) nombres de otras propiedades físicas de los metales, iii) nombres de diferentes tipos de excreción, iv) préstamos, v) procesos, y vi) extensiones al medio ambiente, específicamente, topónimos e hidrónimos (Bellamy, 2018, p. 105). 
En el caso específico del oro, este es descrito en algunas lenguas preferentemente como amarillo, aunque también se lo encuentra denominado por el color rojo. En otras es denominado según su propiedad de brillar o según la percepción de ser una 'piedra bonita', 'heces del sol amarillo', 'excremento de los dioses' o 'excremento del sol'. Por otro lado, en un nivel local, el término para oro se ha transferido de una lengua a otras, como ocurre con el caso del quechua curi (quri), que ha sido tomado en préstamo por varias lenguas de las zonas andinas y amazónicas, a menudo con el mismo significado y poca adaptación fonológica (véase la distribución de préstamos del quechua en Figura 3). ${ }^{7}$

En lo que respecta al mapudungun, hemos rastreado las denominaciones y estrategias denominativas para metales (oro, plata, cobre, estaño y plomo), aleaciones (bronce) y el nombre genérico del metal. Para ello hemos empleado, en primer lugar, diccionarios publicados desde la colonia hasta principios del siglo XX, y, en segundo lugar, diversos textos coloniales y poscoloniales que incluyeran denominaciones diferentes a las identificadas en los diccionarios.

En el caso del oro, la forma más empleada en su denominación corresponde a la palabra milla. Esta es la primera forma registrada en los diccionarios y aparece en todas las obras consultadas. Solo hasta principios del siglo XIX se registran denominaciones alternativas, como chod pañillo (metal amarillo) y el préstamo del español oro (con su variante gráfica orro).

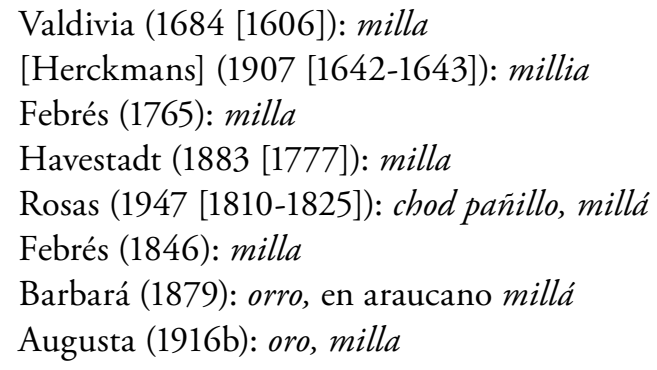

En la denominación de la plata, la primera forma registrada es liqen (con sus variantes gráficas lien, lighen, lighén y lighém). Posteriormente, se registra el préstamo del español plata (con su variante pùlata), documentado a partir de 1846.

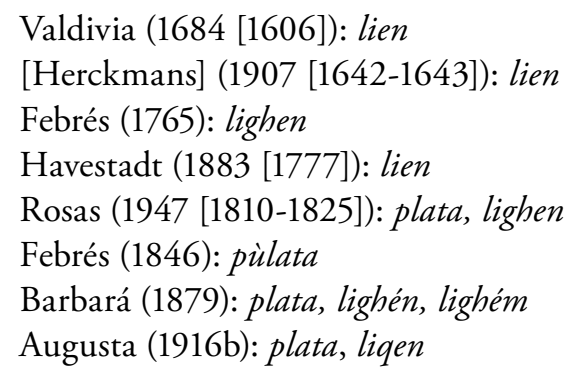

En la denominación del cobre se emplean fundamentalmente las palabras kolü pani lihue (con su variante gráfica kolu pañilwe) y kum/cum pañilwe (con sus variantes cumpañilhue, cumpañillhue y cumpañilhué), ambas con el significado de 'metal colorado'. Más tardíamente fueron registradas las formas kelü pañilwe (metal rojo), payen, y el préstamo del español cofre. Payen

7 Agradecemos a Kate Bellamy habernos facilitado este mapa, que forma parte de su investigación doctoral. 


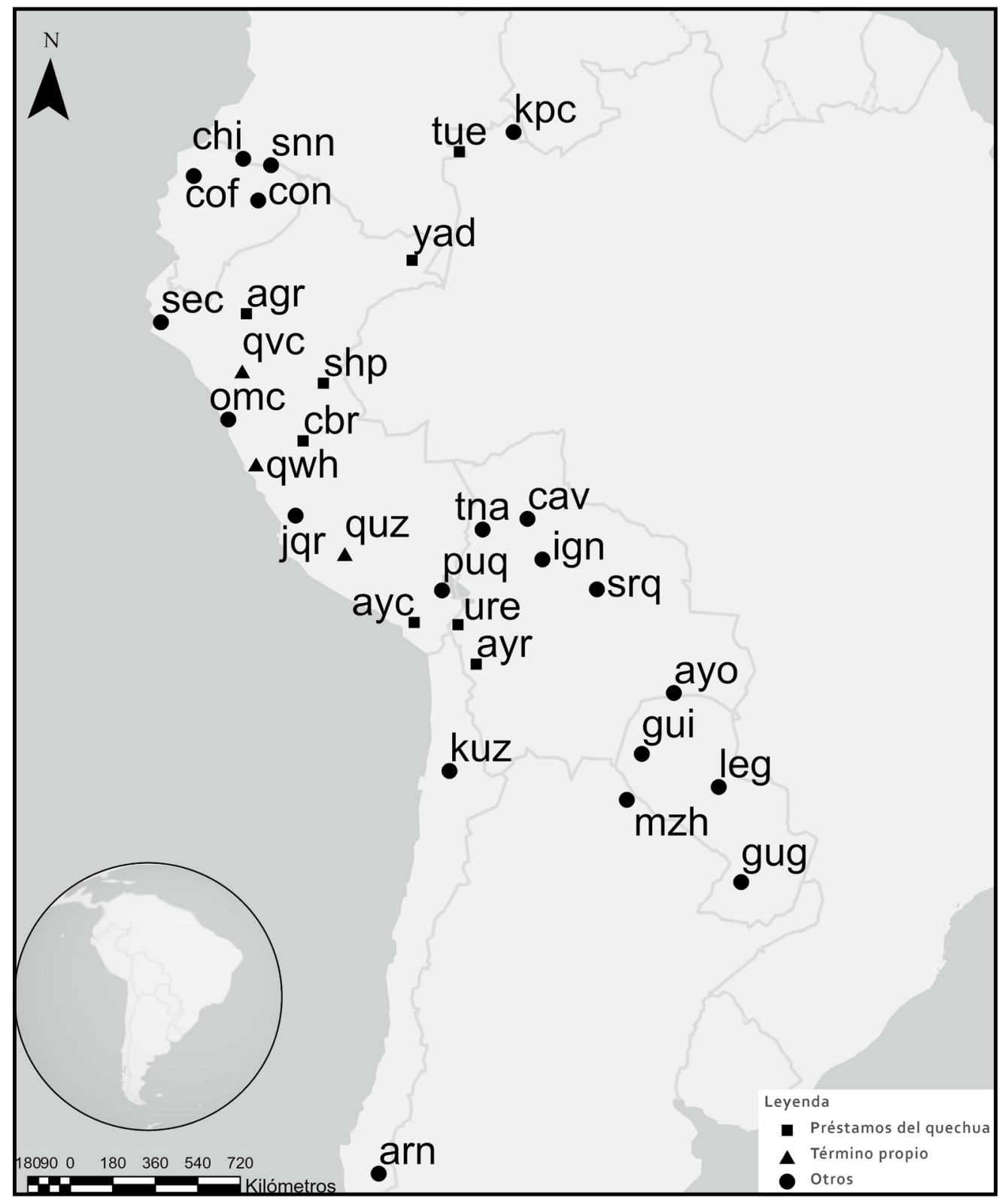

Figura 3. Referenciación geográfica de los términos para 'oro' según Bellamy (2018). 
es también el nombre que recibía una montaña de la provincia de Mendoza, la cual, según Molina y Villarino, tenía reputación de ser una de las minas de cobre más ricas (Molina, 1986 [1810], p. 79; Villarino, 1837, p. IX). Villarino también sostiene que el nombre mapuche para el cobre es cumpañilhue, pero que los pehuenche lo llaman payen, ya sea por una alteración de la palabra pañil (nombre genérico de los metales), o por el color azul (payne) del lapislázuli (abundante también allí) o del cobre de esta montańa, semejante, tal vez, al azulado de otras montańas de cobre en Europa (Villarino, 1837, p. IX).

Valdivia (1684 [1606]): kolu pani lihue, kum pañilibue

Febrés $(1765,1846)$ : cumpañilhue

Havestadt (1883 [1777]): cumpanillhue

Molina (1986 [1810]): payen

Rosas (1947 [1810-1825]): cumpañilhue

Barbará (1879): cofre, cumpañilhué

Augusta (1916b): cofre; kelü pañilwe, kum pañilwe

Con respecto al estaño, en su denominación se emplea fundamentalmente el préstamo del quechua titi (con sus variantes gráficas thithi y tri-tri), unidad léxica que en su lengua de origen designaba tanto el estaño como el plomo (Sánchez, 2014). Tardíamente, en 1916, se registra la palabra liq pañilwe 'metal blanco'.

Valdivia (1684 [1606]): titi

[Herckmans] (1907 [1642-1643]): titi

Febrés (1765): titi, thithi

Havestadt (1883 [1777]): titi

Febrés (1846): titi

Barbará (1879): tri-tri

Augusta (1916b): liq pañilwe

En cuanto al plomo, en su denominación se emplea tanto el quechuismo titi (con sus variantes thithi, riti, ti-tí, tri-tri y tili) (Sánchez, 2014) como las palabras laquir y pakür. Al igual que el estańo, el plomo se utiliza en las soldaduras; motivo por el cual pudieron ser denominados mediante el mismo quechuismo.

Valdivia (1684 [1606]): laquir

Febrés (1765): titi, tritri, laquir

Havestadt (1883 [1777]): laquir

Rosas (1947 [1810-1825]): thithi, titi, riti

Febrés (1846): titi

Barbará (1879): ti-tí, tri-tri, tili, laquir

Augusta (1916b): titi

Moesbach (1930): pakër

Con respecto al bronce, en su denominación se emplea tanto el término chodpañilwe 'metal amarillo' como pafinka (con su variante gráfica pashiyka).

Augusta (1916b): chod pañilwe; pafinka

Moesbach (1930): pashinka 
Por último, en la denominación del término genérico para los metales se emplea principalmente la palabra pañilwe (con sus variantes pañillihue, pañillue, pavillue, panillhue, pañilhue y pañilhué), que en las fuentes consultadas es definida como 'metal', 'hierro' y 'fierro'. Creemos que esta palabra podría haberse formado a partir de la base léxica de pañi= 'la resolana' (Febrés, 1765; Augusta, 1916a), a la cual se pudo haber añadido el sufijo instrumental -we: pañil-we 'objeto que refleja la luz del sol'. Esta forma aparece en todos los diccionarios consultados. Adicionalmente, para el mismo hiperónimo, en el diccionario [de Herckmans] de 1642-1643 se registra también la palabra paila ([Herckmans], 1907 [1642-1643], p. 50) (muy probablemente relacionada con pañilwe); en el de Rosas (1947 [1810-1825]), las formas curru pañille (con sus variantes gráficas curri pañillé, curri pañillue y cürri pañilué) 'metal negro, oscuro' y chodpañillo 'metal amarillo'; y, en el tomo II del diccionario de Augusta, el préstamo del español metal.

Valdivia (1684 [1606]): pañillihue, pañillue 'hierro'

[Herckmans] (1907 [1642-1643]): paila 'el metal, o la mina'; pavillue 'el hierro'

Havestadt (1883 [1777]): panillhue 'fierro'

Febrés (1765): pañilhue 'el fierro'

Rosas (1947 [1810-1825]): pañilhue 'fierro', curru pañille / curri pañillé / curri

pañillue / cürri pañilué 'fierro', chodpañillo 'metal's, amarillo 'metal'

Febrés (1846): pañilhue 'el fierro'

Barbará (1879): pañilhué

Augusta (1916a): pañilwe 'el fierro, el metal'

Augusta (1916b): metal 'metal'

Si relacionamos estos hallazgos con los resultados del trabajo de Bellamy, constatamos que en el mapudungun se emplean tres de las estrategias identificadas por la autora en la denominación de los metales: la creación de palabras mediante recursos propios de la lengua, basándose en el color o bien en propiedades físicas, y la adopción de préstamos, sean estos, para el caso del mapudungun, del quechua o del espańol. En el caso del 'oro', observamos el uso de la primera y la última de estas estrategias. Pero, además, constatamos un grupo de términos, cuya estrategia denominativa no pudimos identificar, dentro del cual se encuentra la palabra milla 'oro', tal como se presenta en la Tabla 1.

8 En esta fuente, contigua a la palabra chodpañillo y separada de esta mediante un guion, aparece la palabra amarillo. Podría ser una glosa de la primera palabra, como también otro hiperónimo para los metales (esta última explicación nos parece menos probable). 
Tabla 1. Estrategias empleadas en la denominación de términos de la metalurgia en mapudungun.

\begin{tabular}{|c|c|c|c|c|c|}
\hline \multirow{3}{*}{$\begin{array}{l}\text { Términos de la } \\
\text { metalurgia }\end{array}$} & \multicolumn{5}{|c|}{ Estrategias denominativas } \\
\hline & \multirow{2}{*}{$\begin{array}{l}\text { Formación } \\
\text { propia basada } \\
\text { en el color }\end{array}$} & \multirow{2}{*}{$\begin{array}{c}\text { Formación } \\
\text { propia basada } \\
\text { en propiedades } \\
\text { físicas }\end{array}$} & \multicolumn{2}{|c|}{ Adopción de préstamos } & \multirow[b]{2}{*}{$\begin{array}{l}\text { Estrategia no } \\
\text { determinada }\end{array}$} \\
\hline & & & Del quechua & Del espańol & \\
\hline 'oro’ & $\begin{array}{c}\text { chod pañillo } \\
\text { 'metal amarillo' } \\
\text { (R1810-1825) }\end{array}$ & & & $\begin{array}{c}\text { oro } \\
(\mathrm{B} 1897, \mathrm{~A} 1916)\end{array}$ & $\begin{array}{c}\text { milla }(\mathrm{V} 1606, \\
\mathrm{H} 1642-1643 \\
\mathrm{~F} 1765, \mathrm{H} 1777, \\
\mathrm{~F} 1846, \mathrm{R} 1810- \\
1825, \mathrm{~B} 1897, \\
\text { A1916) }\end{array}$ \\
\hline 'plata' & $\begin{array}{l}\text { liqen 'que es } \\
\text { blanco' (V1606, } \\
\text { H1642-1643, } \\
\text { F1765, H1777, } \\
\text { R1810-1825, } \\
\text { B1897, A1916) }\end{array}$ & & & $\begin{array}{c}\text { plata (F1846, } \\
\text { R1810-1825, } \\
\text { B1897, A1916) }\end{array}$ & \\
\hline 'cobre' & $\begin{array}{c}\text { kum pañilwe } \\
\text { 'metal colorado' } \\
\text { (V1606, F1765, } \\
\text { H1777, F1846, } \\
\text { R1810-1825, } \\
\text { B1897, A1916) } \\
\text { kolu pani libue } \\
\text { 'metal colorado' } \\
\text { (V1606) } \\
\text { kelü pañilwe } \\
\text { 'metal rojo' } \\
\text { (A1916) }\end{array}$ & & & $\begin{array}{c}\text { cofre } \\
\text { (B1897, A1916) }\end{array}$ & $\begin{array}{c}\text { payen } \\
\text { (M1810) }\end{array}$ \\
\hline 'estaño’ & $\begin{array}{c}\text { liq pañilwe } \\
\text { 'metal blanco' } \\
\text { (A1916) }\end{array}$ & & $\begin{array}{c}\boldsymbol{t i t i}(\mathrm{V} 1606, \\
\mathrm{H} 1642-1643, \\
\text { F1765, H1777, } \\
\text { F1765, F1846, } \\
\text { B1897) }\end{array}$ & & \\
\hline 'plomo' & & & $\begin{array}{c}\boldsymbol{t i t i}(\mathrm{F} 1765, \\
\mathrm{R} 1810-1825, \\
\mathrm{~F} 1846, \mathrm{~B} 1897 \\
\mathrm{~A} 1916)\end{array}$ & & $\begin{array}{c}\text { laquir (V1606, } \\
\text { F1765, H1777, } \\
\text { B1897) } \\
\text { pakër (M1930) }\end{array}$ \\
\hline 'bronce' & $\begin{array}{c}\text { chod pañilwe } \\
\text { 'metal amarillo' } \\
\text { (A1916) }\end{array}$ & & & & $\begin{array}{c}\text { pafiyka (A1916, } \\
\text { M1930) }\end{array}$ \\
\hline 'metal' & $\begin{array}{c}\text { curru pañille } \\
\text { 'metal oscuro' } \\
\text { (R1810-1825) } \\
\text { chodpañillo } \\
\text { 'metal amarillo' } \\
\text { (R1810-1825) }\end{array}$ & $\begin{array}{c}\text { pañilwe 'objeto } \\
\text { que refleja la luz' } \\
\text { (V1606, H1642- } \\
\text { 1643, H1777, } \\
\text { R1810-1825, } \\
\text { F1846, B1879, } \\
\text { A1916) }\end{array}$ & & & $\begin{array}{c}\text { paila } \\
(\mathrm{H} 1642-1643)\end{array}$ \\
\hline
\end{tabular}

Nota 1: En el caso de los términos con más de una variante gráfica, empleamos en el cuadro solo una de ellas. Nota 2: En B1987 también encontramos la palabra nolquer 'alumbre', que podría estar relacionada con laquir y pakür 'plomo'. Nota 3: las siglas de referencias bibliográficas entre paréntesis corresponden a:

A1916: Augusta, 1916a / Augusta, 1916b / B1897: Barbará, 1897/ F1765: Febrés, 1765/ F1846: Febrés, 1846 / H1642-1643: [Herckmans], 1907 [1642-1643] / H1777: Havestadt, 1883 [1777] / M1930: Moesbach, 1930 / M1810: Molina, 1986 [1810] / R1810-1825: Rosas, 1947 [1810-1825] / V1606: Valdivia, 1684 [1606]. 
En síntesis, pues, el mapudungun usa estrategias denominativas previsibles para los metales, basadas en el color $\mathrm{u}$ otras propiedades físicas, toma tempranamente un solo préstamo del quechua para nombrar por igual estaño y plomo, e incorpora tardíamente préstamos del castellano para oro, plata y cobre, posiblemente conforme se castellaniza la población. Milla (junto con otros cuatro vocablos, para cobre, plomo y bronce) no parece ser préstamo y no se puede determinar su origen. Pero, además, tiene una recurrencia mucho mayor que los demás vocablos en cualquier fuente, y, como hemos visto en los apartados anteriores, tiene una significativa presencia en contextos de significación cultural (espiritualidad, onomástica y toponimia), cosa que ningún otro metal posee. Tendríamos en este aspecto, entonces, un argumento más que aboga por considerar la palabra como parte del léxico propio del mapudungun. Conviene, sin embargo, como lo sugiere Fossa con lucidez para el caso quechua-aymara-puquina (Fossa, 2019, pp. 24-25), considerar la coexistencia del mapudungun con estas lenguas, y el contexto lingüístico andino en el período prehispánico y temprano-colonial para tener una mejor comprensión de las interacciones y préstamos que se conocen. El hecho de la expansión del Incario hacia el sur, y que los mapuche hayan tributado oro al Inka, cosa que los españoles pudieron aprovechar, obliga a situar los análisis que hemos presentado hasta ahora en el marco de estos contactos e interacciones entre el mapudungun y el quechua o aymara.

\section{Algunos apuntes sobre el contacto del mapudungun con el quechua o aymara}

El período de expansión inca en Chile va de la década de 1460 a 1536, según fuentes clásicas (Moulian et al., 2015, p. 75), aunque Luis Cornejo (2014) propone al menos cien años antes para el inicio. Esta presencia de hablantes de quechua-aymara explicaría que en el avance militar español, los yanaconas (con Almagro y luego con Valdivia) se hayan podido comunicar con la población local, como lo indican las fuentes, hasta la altura de Copiapó-Coquimbo, aunque al parecer el quechua-aymara coexistía también hasta ahí con lenguas locales relativamente variadas, del área diaguita u otras (Adelaar y Muysken, 2004, p. 177; Hidalgo, 2004), pues Vivar, de hecho, observa que el valle de Atacama "tiene lengua por sí" (Vivar, 1966 [1558], p. 14).

A la altura de Copiapó-Coquimbo, según esta crónica, Pedro de Valdivia, llegando a un valle, pide a los yanaconas que hablen fuerte en la lengua del Cuzco (sic), para ver si se puede entender con la gente de ahí. Responde Ulpar, que se dice capitán de los caciques Gualenica y Aldequin, diciendo que entiende esa lengua, aunque no es la suya, porque cerca tienen un pueblo de gente de Cuzco (Vivar, 1966 [1558], p. 21). Habla con él Valdivia por medio de un intérprete "que sabe la lengua y lenguajes de Copiapó y de toda la tierra" (Vivar, 1966 [1558], p. 22), entre las que podríamos suponer está ya el mapudungun. Más adelante, en el valle del Huasco, dice que no hablan la lengua de Copiapó y que difiere de esta "como en España de viscainos a navarros" (Vivar, 1966 [1558], p. 29). Del valle de Coquimbo, dice que tiene "lengua por si" (Vivar, 1966 [1558], p. 32), al igual que el valle del Limarí (Vivar, 1966 [1558], p. 32). Pero el valle de Aconcagua y el valle "de Mapocho" hablan una misma lengua (Vivar, 1966 [1558], p. 38), que es sin duda mapudungun, pues Michimalonko, cacique de Aconcagua, aliado de los incas (Mitimae-Lonko, posiblemente, según Rueff Keller (1976), lo que significaría que es un nombre compuesto del quechua mitma: aliado y mapudungun lonko: jefe, autoridad), se enfrenta a Valdivia, y lo interpela, según la crónica de Vivar, en esa lengua (Vivar, 1966 [1558], p. 43). El cacique de Quillota, Quilicanta, también nombrado en Vivar, era asimismo gobernador o curaca del Cuzco (Vivar, 1966 [1558], p. 39). Se trata, por lo tanto, de una zona de contacto entre mapudungun y quechua-aymara por la presencia inca, y 
seguramente las primeras comunicaciones entre españoles y mapuche se produjeron por medio de individuos bilingües quechua-mapudungun (Sánchez, 2014).

Según la misma crónica de Vivar, “a siete leguas de la ciudad de Santiago” empieza la provincia de "pormocaes, o pomaucaes (lobos monteses)" que termina en el Maule, y se afirma que hasta ahí llegaron los incas, sin que pasaran más allá (Vivar, 1966 [1558], p. 138). Con la penetración inca hasta el río Maule o hasta el Biobío, y la evidencia de que el mapudungun estaba ya en el valle de Aconcagua, resulta claro que hubo una amplia zona de contacto mapudungun/quechua-aymara, que explica la presencia de abundantes quechuismos-aymarismos en el mapudungun (cf. Pache, 2014). Estas unidades ingresaron al mapudungun por dos vías: la expansión de grupos hablantes de quechua-aymara, y la conquista militar española, que se hizo con tropas auxiliares de indígenas (los llamados yanaconas) de habla quechua o aymara. Si bien algunos autores postulan contactos preincas, ${ }^{9}$ o sugieren contactos por terceras lenguas del subcontinente, el estado de estos estudios y las limitaciones disciplinares propias no nos autorizan a incorporar estas hipótesis, de modo que aquí nos limitamos a señalar las dos posibilidades conocidas: la del contacto inca-mapuche, y del contacto español-mapuche mediado por el quechua. ${ }^{10}$

La presencia de quechuismos en el mapudungun fue señalada ya por los primeros gramáticos: Valdivia (1684 [1606]), Febrés (1765), Havestadt (1883 [1777]), e incluso el Vocabulario Araucano de Elias Herckmans (1907 [1642-1643]), y la confirmaron los estudiosos de fines del XIX y comienzos del XX (Augusta, 1916a, 1916b; Englert, 1934; Lenz, 1979). En tiempos recientes ha sido actualizada por A. Díaz-Fernández (1992) y L. Golluscio (2009), pero sobre todo por G. Sánchez (2014), y por T. Dillehay y Gordon (1998), que han proporcionado datos para la arqueología y han servido de punto de partida para estudios antropológicos y lingüísticos de los últimos ańos, como los de W. Adelaar (2009), R. Moulian, M. Catrileo, P. Landeo y F. Hasler (Moulian et al., 2015, 2018; Moulian y Catrileo, 2013) y de M. Pache (2014). Esta influencia del quechua también se hizo sentir en el castellano de Chile, y es posible que haya habido trasvases de préstamos quechua-aymaras entre el castellano y el mapudungun. Asimismo, la presencia de topónimos quechua en el territorio chileno está documentada en F. Solano Asta-Buruaga (1867), P. Armengol (1918) y L. Riso Patrón (1924), y hay toponimia de lugares de minas que es claramente quechua o aymara, con el sustrato de la palabra coya (veta o mina), como pueden ser Quilacoya o Coya, y posiblemente del radical chu, o chuqui, como Chuquicamata y Choquelimpe.

Teniendo en cuenta que no hay investigaciones sobre la vitalidad y posterior pérdida del mapudungun en los territorios en que fue lengua principal, no se puede sino reconocer que hará falta nuevos estudios para seguir profundizando en la relación histórica entre el mapudungun y las demás lenguas con las que tuvo contacto, y llegar a conclusiones más sólidas para el caso que nos ocupa.

9 La relación genética entre quechua-aymara y mapudungun está descartada (Adelaar, 2004; Pache, 2014), aunque según ellos hay paralelismos que denotan un contacto pre-inca.

10 Dejamos para una futura exploración las sugerentes, aunque difíciles de establecer por nuestra parte, asociaciones posibles de milla con el quechua y aymara ylla (Moulian et al., 2018). Asimismo, queda para un ulterior trabajo las asociaciones que en otras lenguas americanas vinculan el oro con los excrementos (Bellamy, 2018), y que incluso se advierten en mitos como el de "El monstruo de la bosta de oro", al que nos hemos referido en estas páginas. 


\section{Consideraciones finales}

El repaso de las fuentes que hemos realizado hasta aquí nos permite afirmar con razonable certeza que milla es una palabra monomorfémica, y que no hay evidencia de que no sea una palabra del léxico original del mapudungun, lo que confirmaría que el oro era conocido antes de la explotación minera inca en territorio mapuche, sea con el sentido de oro metálico o resplandor dorado, o con ambos significados, y con atributos positivos, que seguramente se reforzaron por la demanda inca, y luego española, del metal.

Lingüísticamente la palabra exhibe una gran estabilidad, incluso rodeada de préstamos. Aunque el fonema /ll/ es casi exclusivamente andino (Andrés Salanova, com. pers., 5 de mayo 2019), la relación con el quechua o aymara está descartada en el caso de esta palabra, salvo que pudiera demostrarse que fuese, por ejemplo, una formación neológica derivada del término quechua y aymara illa o ylla, cosa que especialistas rigurosos como Cerrón Palomino (2010) no han planteado, y que tampoco reconoce la memoria oral. También se descarta que sea préstamo de alguna otra lengua cercana.

La presencia notable de milla en la antroponimia mapuche tanto al norte como al sur del Biobío no deja lugar a dudas sobre esta estabilidad lingüística y la extensión y univocidad del sentido. La asociación entre antropónimos y lugares donde hay oro es sugestiva, pero ni histórica ni antropológicamente se ha planteado esta asociación, ni para milla ni para otros radicales que componen los nombres de personas.

La toponimia con milla es claramente deíctica, es decir, coincidente con lugares donde hay oro. Además, la presencia de topónimos repetidos como Millahue (lit. 'lugar donde hay oro'), y algunos informes personales recabados en la zona de Temuco confirman la existencia de una toponimia menor relacionada con este. Dada la costumbre de guardar en sigilo la información sobre lugares de oro, es posible que la toponimia conocida sea la que no se pudo ocultar.

Los informes históricos sobre los usos de oro como metal en la cultura mapuche son suficientes como para pensar que hubo aprecio por el metal; sin embargo, al no existir oro arqueológico, no permitiría concluir la valoración que puede haber tenido. Nos parece significativa, sin embargo, la recurrencia de milla en el lenguaje de machi, testimonio de una relación con lo sobrenatural que, por lo mismo, no puede ser sino antigua. Incluso las co-ocurrencias de milla con préstamos del castellano (bandera, seña, cuchillo, escalera) que aparecen en las rogativas de machi mencionadas en este estudio parecen confirmar el poder de la palabra.

Sabemos, por la documentación histórica, que se forzó a los indígenas a extraer oro, primero por los incas y luego por los españoles, y que esta actividad forzada fue causa de alzamientos durante el período colonial; pero aunque podamos suponer que ahí radica el desinterés que hasta la actualidad manifiesta la sociedad mapuche por el oro, no hay fuentes que ofrezcan claves para entender ese proceso (aunque, como hemos visto, las crónicas de viajeros de mediados del siglo XIX señalan este desinterés con algo de curiosidad).

Con esta información hemos hecho consultas en entrevistas personales con estudiosos y kimche mapuche, expertos en el conocimiento o kimün autóctono quienes, desde su conocimiento de las conductas históricas ante el contacto y la conquista, apuntan a suponer un uso autóctono del oro y un trauma asociado al hecho de que se les despoja de aquel y se les obliga a extraerlo, 
como hemos dicho, primero bajo el dominio de los incas, y luego bajo el de los españoles. Es posible que esa percepción traumática se haya difundido de generación en generación. La evidencia arqueológica hasta ahora, sin embargo, no permite dar sustento a esta hipótesis procedente de la memoria oral.

Estas consultas, realizadas al kimche don Florencio Manquilef y al filósofo Ramón Curivil, ambos de la zona del Budi, y este último, autor de importantes trabajos sobre la espiritualidad mapuche, nos incitan a proponer una exploración en el sentido de que en la cosmovisión mapuche toda entidad natural está protegida por fuerzas o seres espirituales, los ngen. Agua, tierra, bosques, montes tienen sus ngen (Curivil, 2007, 2008). En la lucha actual por la preservación de los lugares naturales, de los que los mapuche dependen para la obtención de bienes culturales, salud y fuerza espiritual, es frecuente, al lamentar la pérdida, decir que los ngen han abandonado esos lugares, pues se han vuelto estériles. Una vez que los ngen dejan estos lugares y elementos naturales, pierden su significación y carácter sagrado para la población. Tendría entonces sentido que se hayan abandonado los lugares de oro, cerrado las minas, y explicaría incluso la prohibición de acercarse a ellas. Dicho de otra manera, aquello que el wingka, el blanco, requisó, e hizo explotar a costa de tanto dolor, dejó de estar protegido por los ngen. Y una vez abandonado por los ngen, dejó de tener sentido para los mapuche.

Salvo por la inexistencia de restos de oro arqueológico, dato ineludible, desde luego, nada parece indicar que los mapuche no hayan tenido algún aprecio por el oro en épocas prehispánicas. Puede no haberles interesado su explotación, del mismo modo que no explotaban ningún otro elemento de la naturaleza. Es más, reverenciaban, y siguen reverenciando, todo lo que la naturaleza produce. Las primeras crónicas mencionan que algo de oro llevaban en la indumentaria, y en ellas figuran nombres propios compuestos de milla, lo que no puede interpretarse sino como signo de importancia (al igual que los compuestos por kura= piedra). Aun en relaciones elaboradas poscontacto, está registrado en la memoria oral de los ngillatun que los lugares donde viven los espíritus que luego la religión católica demonizó tienen un piso (tafü) de oro, y el ngillatun mismo se hace ya sea en una pampa de oro, o en una pampa del pillan. Algunas rogativas de machi relacionadas con los kuel, aun en tiempos recientes, contienen, como hemos dicho, numerosas referencias al oro. Parece, por lo tanto, demostrada la relación de milla con elementos de la cosmovisión indígena, de origen incierto. El hecho de que incas y luego espańoles hayan requisado todo el oro visible y que hayan obligado a los indígenas a abandonar su tierra, su mapu, para trabajar en los lavaderos debe forzosamente haber tenido un impacto que no se ha aquilatado debidamente.

En una sociedad en que las decisiones importantes se consultan con machi, y donde el pewma, o sueño, interviene en decisiones individuales y colectivas, ¿`cómo se ha de haber procesado el despojo del oro, y el afán por el oro de incas y españoles? ¿Con qué recursos culturales se habrá solventado el conflicto? ¿Puede haber causado en la sociedad mapuche una respuesta afín a la que se observa en el abandono de espacios naturales cuyos ngen han decidido que ya no son habitables? ¿Habrá sido una solución hacer del oro un tabú? Abandonando el interés por el oro, ¿se habrá pretendido frenar la violencia?, ¿evitar la esclavitud y la sumisión?

Y, entonces, ¿qué claves podría haber en el uso de la plata? Sabemos que hacia fines del siglo XVIII, con la difusión de la moneda, la plata (lig) toma el lugar ornamental que podría haber tenido el oro, pero sin que aparezca en la toponimia (obvio, no hay minas en territorio mapuche) ni en la antroponimia. Más allá del valor ornamental (la usan en ornamentos de mujeres 
-salvo aretes en hombres- y de caballos), también le dieron valor simbólico: la plata como escudo o protección (Mora, 1986, p. 39), y hemos tenido ocasión de admirar en el Museo Regional de la Araucanía (Temuco) un extraordinario tüpü, o broche pectoral circular, en plata del siglo XIX, que lleva grabada en forma precisa la distribución de los rewe en un territorio. ¿De dónde provienen estos diseños? ¿Pudo acaso tener algún modelo en oro esta joyería que contiene importantes elementos cosmovisionarios, hecha en un metal no autóctono? Y, extrapolando nuestro interés, ¿qué valores cosmovisionarios y sociopolíticos se habrán transferido a adquisiciones culturales que hicieron los mapuche a partir del contacto, como el cuchillo o la bandera, que aparecen junto con milla en las oraciones de machi?

Hasta aquí llega nuestra indagación. A lo largo de este repaso de fuentes, nos ha guiado el interés de penetrar en lo que unos y otros entendieron por oro, determinar la valoración que tuvo para la cultura mapuche a partir de la huella que dejó en la lengua y rastrear lo que parece haber sido un cambio en la valoración: del aprecio al desprecio. Estamos aún lejos de comprender los mecanismos de acoplamiento, resistencia, adaptación y rechazo que esta sociedad indígena creó, o a los que recurrió, mecanismos que seguramente guardaban coherencia con los recursos culturales que le eran propios y naturales.

\section{Agradecimientos}

Agradecemos a la Agencia Nacional de Investigación y Desarrollo (ANID) del Gobierno de Chile el financiamiento otorgado a esta investigación en el marco del Proyecto FONDECYT Regular 1170551 (2017-2020), “Tras la ruta del oro. Los habitantes de La Araucanía frente a la ocupación española del siglo XVI, recepción, adaptación y resistencia”, bajo la dirección de José Manuel Zavala.

Agradecemos asimismo a los evaluadores los comentarios y sugerencias al manuscrito.

\section{Referencias citadas}

Adelaar, W. F. H. (2009). Inverse Markers in Andean Languages: A Comparative View. En Wetzels, W. L. M. (Ed.). The Linguistics of Endangered Languages: Contributions to Morphology and Morpho-Syntax (pp. 171-185). Utrecht: LOT Occasional Series, 13.

Adelaar, W. y Muysken, P. (2004). The Languages of the Andes. Cambridge: Cambridge University Press. doi:10.1017/CBO9780511486852

Ajens, A. (2017). Conexiones huilliche-altoperuanas en el ciclo de Atahualpa. Meridional Revista Chilena de Estudios Latinoamericanos, 8, 153-188.

Alcamán, E. (Ed.). (2017). Apellidos mapuche-williches identificados en la Región de los Lagos. Temuco: Corporación Nacional de Desarrollo Indígena, CONADI.

Anónimo (Blas Valera). (2014 [1586]). Arte, y vocabvlario en la lengva general del Perv llamada quichua, y en la lengua española. En Cerrón, R. (Ed.). Lima: I.R.A./ PUCP.

Armengol Valenzuela, P. (1918). Glosario Etimológico de Nombres de Hombres, Animales, Plantas, Ríos y Lugares, y de vocablos incorporados en el Lenguaje Vulgar, aborigenes de Chile, y de algún otro país americano. Santiago: Imprenta Universitaria. 
Augusta, F. de (1907). ¿Cómo se llaman los araucanos? Valdivia: Imprenta San Francisco.

Augusta, F. de (1910). Lecturas araucanas. Valdivia: Imprenta de la Prefectura Apostólica.

Augusta, F. de (1916a). Diccionario Araucano-Español. Tomo I. Santiago: Imprenta Universitaria.

Augusta, F. de (1916b). Diccionario Español-Araucano. Tomo II. Santiago: Imprenta Universitaria.

Augusta, F. de (1934). Lecturas araucanas. Padre Las Casas: Editorial San Francisco.

Baker, M. y Fasola, R. (2009). Araucanian: Mapudungun. En Lieber, R. y Stekauer, P. (Eds.). The Oxford Handbook of Compounding (pp. 594-608). Oxford: OUP.

Barbará, F. (1879). Manual o Vocabulario de la lengua Pampa y del Estilo Familiar. Para el uso de los jefes y oficiales del ejército, y de las familias a cuyo cargo están los indígenas. Buenos Aires: Imprenta y Librería de Mayo.

Bellamy, K. (2018). On the External Relations of Purepecha. An Investigation into Classification, Contact and Pattern of Word Formation. Tesis doctoral. Leiden University, Utrecht, Países Bajos.

Bertonio, L. (1612). Vocabulario de la lengua aymara. Juli, Provincia de Chucuito: Casa de la Compañía de Jesús, Francisco del Canto.

Catriquir, D. y Durán, T. (1990). El nombre personal en la sociedad y cultura mapuche. Implicancias étnicas y educacionales. Actas de Lengua y Literatura Mapuche, 4, 257-275.

Cerrón Palomino, R. (2010). Contactos y desplazamientos lingüísticos en los Andes Centro-Sureños: el puquina, el aimara y el quechua. Boletín de Arqueología PUCP, 14, 255-282.

Cerrón Palomino, R. (2015). Toponimia andina: problemas y métodos. Lexis, 39(1), 183-197.

Contreras, C. (1991). El mito del Rey-Inca entre los huilliches. Revista Nütram, VII(1), 14-32.

Contreras Cruces, H. (2017). Oro, tierras e indios. Encomienda de servicio personaly comunidades indigenas en Chile central, 1541-1580. Santiago: Ediciones Universidad Academia de Humanismo Cristiano.

Cornejo, L. (2014). Sobre la cronología del inicio de la imposición cuzqueña en Chile. Estudios Atacameños. Arqueologia y Antropología Surandinas, 47, 101-116.

Curivil, R. (2007). La fuerza de la religión de la tierra: una herencia de nuestros antepasados. Santiago: Ediciones Universidad Católica Raúl Silva Henríquez.

Curivil, R. (2008). Cultura mapuche: un antiguo ideal de persona para una nueva historia. CUHSO, 16(2), $37-52$.

Díaz-Fernández, A. (1992). Contactos del mapudungun con dos lenguas principales del Tawantinsuyu: el quechua y el yunga. Actas de Lengua y Literatura Mapuche, 5, 193-201.

Dillehay, T. (2007). Monuments, Empires and Resistance. The Araucanian Polity and Ritual Narratives. Cambridge: Cambridge University Press.

Dillehay, T. y Gordon, A. (1998). La actividad prehispánica de los Incas y su influencia en la Araucanía. En Dillehay, T. y Netherly, P. (Eds.). La frontera del estado Inca (pp. 183-97). Quito: Fundación Alexander von Humboldt - Editorial Abya-Yala. 
Englert, S. (1934). Los elementos derivados del Aymará y Quichua en el idioma Araucano: Araucano y Rapanui. Santiago: Prensas de la Universidad de Chile.

Ercilla, A. de (1776 [1574]). La Araucana. Madrid: Antonio de Sancha.

Febrés, A. (1765). Arte de la Lengua General del Reyno de Chile, con un dialogo Chileno-Hispano muy curioso: a que se añade la Doctrina Christiana, esto es, Rezo, Catecismo, Coplas, Confesionario, y Pláticas; lo mas en lengua Chilena y Castellana: y por fin un vocabulario. Lima: Imprenta Calle de la Encarnación.

Febrés, A. (1846). Diccionario Chileno Hispano, compuesto por el R.P. Misionero Andres Febres de la C. de J. Enriquecido de voces i mejorado por el R.P. Misionero Fr. Antonio Hernández i Calzada de la órden de la Regular Observancia de N.P.S. Francisco. Edicion hecha para el servicio de las Misiones por órden del Supremo Gobierno i bajo la inspeccion del R.P. Misionero Fr. Miguel Anjel Astraldi. Santiago: Imprenta de los Tribunales.

Foerster, R. (2010). Acerca de los nombres de las personas (üy) entre los mapuches. Otra vuelta de tuerca. Revista Chilena de Antropología, 21, 1er semestre, 81-110. https://doi.org/10.5354/0719-1472.2011.14111

Fossa, L. (2019). Bajo el cielo de Chuqikirau. Lima: Horizonte.

Gay, C. (1845). Atlas de la historia física y politica de Chile. Tomo II. París: Imprenta de E. Thunot.

Gentile, M. (2007). Un relato histórico incaico y su metáfora gráfica. Espéculo. Revista de Estudios Literarios, 36, 1-16.

Golluscio, L. (2009). Loanwords in Mapudungun, a Language of Chile and Argentina. En Haspelmath, M. y Tadmor, U. (Eds.). Loanwords in the World's Languages: a Comparative Handbook (pp. 1035-1071). Boston: De Gruyter Mouton.

González de Holguín, D. (1989 [1608]). Vocabulario de la Lengva General de todo el Peru llamada Lengua Qquichua o del Inca. Lima: Universidad Nacional Mayor de San Marcos.

Gutiérrez Merino, G. (1990). Dios o el oro de las Indias. Salamanca: Siglo XXI.

Hassler, W. A. (2014). Nguillatunes del Neuquén. Buenos Aires: Grupo Editor Universitario.

Havestadt, B. (1883 [1777]). Chilidúgú sive tractatus linguae chilensis. Leipzig: Edición facsimilar de Julius Platzmann. B.G.Teubner.

[Herckmans, Elias] Schuller, R. R. (1907 [1642-1643]). El Vocabulario Araucano de 1642-1643. Bibliografía de la Lengua Mapuche o Araucana. Santiago: Imprenta Cervantes.

Hidalgo, J. (2004). Historia andina en Chile. Santiago: Universitaria.

Hurtado de Mendoza, G. (1888-1902 [1558]). Carta al Consejo de Indias, 20 de abril de 1558. En Medina, T. J. (Ed.). Colección de documentos inéditos para la historia de Chile: desde el viaje de Magallanes hasta la batalla de Maipo: 1518-1818. Tomo 28. Jerónimo de Alderete y García Hurtado de Mendoza (p. 158). Santiago: Imprenta Ercilla.

Inostroza, I. (2010). La civilización agrominera y comercial mapuche, siglo XVI. Andes del Sur, 1, 20-55. UFRO.

Keller, R. (1976). Michimalonco, Pedro de Valdivia y el nacimiento del pueblo chileno. San Felipe: Sociedad de Historia y Arqueología de Aconcagua. 
Koessler-Ilg, B. (1954). Cuentan los araucanos. Buenos Aires: Espasa-Calpe.

Latcham, R. (1924). La organización y las creencias religiosas de los antiguos araucanos. Santiago: Imprenta Cervantes.

Lenz, R. (1897). Estudios araucanos: materiales para el estudio de la lengua, la literatura i las costumbres de los indios mapuche o araucanos. Diálogos en cuatro dialectos, cuentos populares, narraciones historicas $i$ descriptivas i cantos de los indios. Santiago: Imprenta Cervantes.

Lenz, R. (1979 [1905-1910]). Diccionario etimologico de las voces chilenas derivadas de las lenguas indígenas americanas. Ferreccio, M. (Ed.). Santiago: Universidad de Chile; Seminario de Filología Hispánica.

Mariño de Lobera, P. (1865 [1595]). Crónica del Reino de Chile. Dirijida al Exmo. Señor Don García Hurtado de Mendoza, Marques de Cañete, vice-rei y capitan jeneral de los Reinos del Perú y Chile. Santiago: Imprenta del Ferrocarril.

Medina, J. T. (1882). Los aborijenes de Chile. Santiago: Gutenberg.

Meyer Rusca, W. (1952). Los huilliches a través de sus apellidos. Estudio etimológico de los patronímicos aborigenes sureños. Osorno: Imprenta San Francisco.

Moesbach, E. de. (1930). Vida y costumbres de los indigenas araucanos en la segunda mitad del siglo XIX. Santiago: Imprenta Cervantes.

Molina, J. I. (1986 [1810]). Ensayo sobre la Historia Natural de Chile. Santiago: Ediciones Maule.

Molina, J. I. (2016 [1788]). Compendio de la historia geográfica natural y civil del reino de Chile. Santiago: Pehuén.

Montecino, S. (2015). Mitos de Chile. Enciclopedia de seres, apariciones y encantos. Santiago: Catalonia.

Mora, Z. (1986). La plata y su vinculación al universo femenino de la magia. En Inostroza, J. y Mora, H. (Eds.). Tesoros de la Araucania (pp. 34-48). Temuco: Ilustre Municipalidad de Los Ángeles - Museo Regional de La Araucanía.

Moulian, R. y Catrileo, M. (2013). Kamaska, Kamarikun y Müchulla: Préstamos lingüísticos y encrucijadas de sentido en el espacio centro y sur andino. Alpha, 37, 249-263. ULAGOS.

Moulian, R., Catrileo, M., Hasler, F. y Caniguan, J. (2018). Resonancias de la luz en las lenguas centro y sur andinas: un estudio de correlaciones en constelaciones semióticas amerindias del brillo. ONOMÁZEIN, 42, 125-152. PUC.

Moulian, R., Catrileo, M. y Landeo, P. (2015). Afines quechua en el vocabulario mapuche de Luis de Valdivia. $R L A, 53(2), 73-96$. ISSN 0033-698X

Munita, D., Mera, R., Figueroa, V. y Mille, B. (2009). Evidencias tempranas del trabajo de metales en la Araucanía. Adornos de cobre en el complejo Pitrén. En Vetter, L. (Ed.). Actas del II Congreso Latinoamericano de Arqueometría (pp. 87-100). Lima: Universidad Nacional de Ingeniería.

Olivari Ortega, J. (1994). El oro entre los Incas. Boletin de Lima, XVI(91-96), 205-224.

Pache, M. (2014). Lexical Evidence for Pre-Inca Language Contact of Mapudungun (Mapuche) with Quechuan and Aymaran. Journal of Language Contact, 7(2), 345-379. 
Parodi, C. (2009) La semántica cultural: Un modelo de contacto lingüístico y Las Casas. En Dakin, K., Montes de Oca, M. y Parodi, C. (Eds.). Visiones del encuentro de dos mundos en América (pp. 19-45). México: UNAM.

Payàs, G. (Ed.). (2018). Los Parlamentos Hispano-Mapuches, 1593-1803: Textos Fundamentales: versión para la lectura actual. Santiago: Centro de Investigaciones Diego Barros Arana - DIBAM.

Payàs, G., Zavala, J. M. y Curivil, R. (2014). La palabra "parlamento” y su equivalente en mapudungun en los ámbitos colonial y republicano. Un estudio sobre fuentes chilenas bilingües y de traducción. Historia, 47(2), 355-373. PUC.

Reuel Smith, E. (1914). Los araucanos, o notas sobre una gira efectuada entre las tribus indigenas del Chile Meridional. Santiago: Imprenta Universitaria.

Riso Patrón, L. (1924). Diccionario geográfico de Chile. Santiago: Imprenta Universitaria.

Rosas, J. M. de (1947 [1810-1825]). Gramática y diccionario de la lengua pampa (pampa-ranquel-araucano). Buenos Aires: Albatros.

Sánchez, G. (2014). Los quechuismos en el mapuche (mapudungun(n)), antiguo y moderno, de Chile. IX Congreso Internacional de Lexicología y Lexicografía. En Homenaje a Enrique Carrión Ordónez. Lima.

Solano Asta-Buruaga y Cienfuegos, F. (1867). Diccionario jeográfico de la República de Chile. Nueva York, NY: D. Appleton.

Tangol, N. (1976). Diccionario etimológico chilote. Santiago: Nascimento.

Valdivia, L. de (1684 [1606]). Arte y gramatica general de la Lengua que corre en todo el Reyno de Chile, con un Vocabulario, y Confessionario. Sevilla: Thomás Lopez de Haro.

Valdivia, L. de (1897 [1621]). Nueve sermones en lengua de Chile por el Padre Luis de Valdivia de la Compañia de Jesús. Reimpresos a plana y renglón del único ejemplar conocido y precedidos de una bibliografía por José Toribio Medina. Santiago: Imprenta Elzeviriana.

Villarino, B. (1837). Diario de la navegación emprendida en 1781, desde el Río Negro para reconocer la Bahía de Todos los Santos, las Islas del Buen Suceso, y el desagüe del Río Colorado. Buenos Aires: Imprenta del Estado.

Vivar, J. (1966 [1558]). Crónica y relación copiosa y verdadera de los reinos de Chile. Santiago: Fondo Histórico y Bibliográfico José Toribio Medina - Instituto Geográfico Militar.

Zavala, J. M. (2015). Los parlamentos hispano-mapuches (1593-1803). Textos fundamentales. Temuco: Ediciones Universidad Católica de Temuco.

Zavala, J. M., Dillehay, T. D. y Payàs, G. (Eds.) (2020). The Hispanic-Mapuche Parlamentos: Interethnic GeoPolitics and Concessionary Spaces in Colonial America. Cham: Springer Verlag, 2020.

Zúñiga, F. (2014). Nominal compounds in Mapudungun. En Danielsen, S., Hannss, K. y Zúñiga, F. (Eds.). Word Formation in South American Languages. Studies in Language Companion Series (pp. 11-31). Amsterdam: John Benjamins. 